\section{PRESUPUESTOS JURÍDICOS VINCULADOS AL CONTROL ECOLÓGICO COMO ACTIVIDAD DE LOS SERVICIOS PÚBLICOS AMBIENTALES. UNA MIRADA DESDE EL SECTOR EMPRESARIAL ESTATAL CUBANO}

\author{
BUDGETS LEGAL LINKED TO ENVIRONMENTAL \\ MONITORING AS AN ACTIVITY OF \\ ENVIRONMENTAL UTILITIES. A LOOK FROM \\ THE CUBAN STATE ENTERPRISE SECTOR
}

\author{
ORCAMENTOS LEGAIS LIGADOS À ATIVIDA- \\ DE ECOLÓGICA DE CONTROLE DE SERVIÇOS \\ PÚBLICOS AMBIENTAIS. UM OLHAR DO SECTOR \\ EMPRESARIAL DO ESTADO CUBANO
}

Alcides Francisco Antúnez Sánchez ${ }^{a}$ aantunez@udg.co.cu Elena Polo Maceiras ${ }^{b}$ epolo@fd.uo.edu.cu Yomisel Galindo Rodríguez ${ }^{c}$ ygalindor@udg.co.cu

Fecha de recepción: 5 de Mayo 2014 Fecha de revisión:28 de Mayo 2014 Fecha de aceptación: 4 de Junio 2014

\title{
RESUMEN
}

El control ambiental en Cuba parte de normativas relacionadas con la materia ambiental a partir del triunfo revolucionario en1959, con la reorganización de la Administración Pública, trazando políticas y estrategias para preservar los recursos naturales, alpromulgarse la Ley No. 81 a través del Ministerio de Ciencias, Tecnología y Medio Ambiente.

Con la implementación de la auditoría en el país como actividad de control, a tenor de la Ley No. 107, para ejercitar el más alto control estatal y con ello el control ambiental como una de las herramientas de gestión.

* Este artículo es parte de la investigación vinculada a la tesis doctoral sobre la Auditoria Ambiental en Cuba, realizada por la Facultad de Derecho, en el departamento de Derecho de la Empresa, Universidad de Oriente, que concluye en este 2014.

a. MSc. Alcides Francisco Antúnez Sánchez. Profesor Auxiliar. Carrera de Derecho. Facultad de Ciencias Sociales y Humanísticas. Universidad de Granma. República de Cuba. Email: aantunez@udg.co.cu

b. Dra.C. Elena Polo Maceiras. Profesora Titular. Facultad de Derecho. Universidad de Oriente. República de Cuba.Email: epolo@fd.uo.edu.cu

c. MSc. Yomisel Galindo Rodríguez. Profesor Asistente. Carrera de Derecho. Facultad de Ciencias Sociales y Humanísticas. Universidad de Granma. República de Cuba. Email: ygalindor@udg.co.cu

MISIÓN JURÍDICA

政 Bogotá, D.C. (Colombia)

Colaboradores Externos Internacionales Núm. 7, Año 2014

enero-diciembre, pp. 119-141.

ISSN 1794-600X 
El derecho administrativo, eje trasversal de la actividad pública estatal, irradia para la consecución de las funciones públicas a ejercitar por la Administración hacia sus administrados, relacionadas con el control ecológico para el desarrollo sostenible, tributario al desarrollo local en correspondencia con la política trazada en el modelo económico a través de los Lineamientos adoptados en el 6to Congreso del Partido Comunista de Cuba a partir del año 2012.

\section{PALABRAS CLAVE}

control ambiental, servicios públicos, auditoría ambiental.

\section{ABSTRACT \\ Judicial budget bound to environment control as an activity of environmental public services. A view from the Cuban State business sector. \\ Environmental control in Cuba originates in norms related to environmental matter from the revolutionary triumph in 1959 with the reorganization of Public Administration tracing politics and strategies to preserve natural resources when Law No. 81 came into force through the Ministry of Science, Technology and Environment.}

With the implementation of the audit in the country as an activity of control in the light of Law No. 107, to exercise the highest State control and with it to set the environmental control as a management tool.

The administrative law, cross-curricular theme of the State public activity, irradiates for the achievement of the public functions to exercise by the administration to the governed, associated to environment control towards sustainable development, tributary to local development in connection with the policy traced in the economic model through the Guidelines adopted in the 6th Congress of the Cuban Comunist Party from year 2012.

\section{KEY WORDS}

Environment control, public services, environmental audit.

\section{RESUMO}

O controle ambiental em Cuba é baseado em regulamentações relacionadas a questões ambientais a partir da vitória revolucionária em 1959, com a reorganização da Administração Pública definindo políticas e estratégias para preservar os recursos naturais, com a promulgação da lei no 81, através do Ministério da Ciência, Tecnologia e do Meio Ambiente.

Com a implementação da auditoria no país como atividade de controle, de acordo com a Lei No. 107, a fim de exercer o mais alto controle estatal e, portanto, o controle ambiental como ferramenta de gestão.

0 Direito Administrativo, eixo transversal da atividade pública do Estado, irradia-se para a realização de funções públicas a serem exercidas pela administração, direcionadas a seus gerenciados e relacionadas ao controle ecológico imposto de desenvolvimento sustentável para o crescimento local, em conformidade com a política descrita no modelo económico, através das orientações adotadas para o 6을 Congresso do Partido Comunista de Cuba, a partir do ano de 2012.

\section{PALAVRAS-CHAVE}

Controle ambiental, serviços públicos, auditoria ambiental.

\section{METODOLOGIA}

Nos apoyamos para la ejecución del artículo en métodos científicos de apoyo a la investigación como el histórico lógico, el exegético-jurídico, así como en el análisis y revisión de documentos científicos relacionados con la economía, las ciencias sociales y las jurídicas.

\section{RESULTADOS}

La legislación en materia ambiental en Cuba necesita actualización y evolución, a tono con las situaciones fácticas implementadas y con solución en otros sistemas de derecho que han sido contrastados por los autores de este material, por cuanto los principios jurídicos y la consolidación de las técnicas jurídicas relacionadas con la tutela del control ambiental, están hoy en contradicción. 
Se encuentra que las ciencias jurídicas y las ciencias contables, deberán marchar unidos en pos de un desarrollo y equilibrio sustentable para preservar el medio ambiente. La ecotributación, modernizada con la implementación a tenor de la Ley No. 113, tendrá que ser contextualizada por el empresariado cubano, para coadyuvar a mitigar los problemas ambientales.

\section{INTRODUCCIÓN}

La Constitución de 1976, institucional y jurídicamente, asume la tutela en materia de protección de la naturaleza y de sus recursos naturales tanto por el Estado en $\mathrm{Cuba}^{1}$, como por los ciudadanos con un sentido socializador. Esto en consonancia con lo aprobado en la Cumbre de Río de Janeiro en el año $1992^{2}$, contextualizado

1 HERNANDEZ AGUILAR, Orisel y otros. "Retos ambientales para la constitución" Principales omisiones del texto constitucional en materia ambiental a criterio de la autora, coinciden estos investigadores que deberán abordarse cuando se decida por parte del Estado cubano. Proyecto ECOIURE. UNJC. Cuba. Editora PALCOGRAF.2011. hptt/www.unjc.cu pp.11-27 Son coincidentes REY SANTOS, Orlando. "Los retos en la implementación del derecho ambiental en Cuba". Acerca de los retos y tendencias del Derecho Ambiental contemporáneo. Proyecto ECOIURE-UNJC. Editora Palcograf. Cuba.2011.pp.11-27 Email:rey@citma.cu. 2013. PEREZ HERNANDEZ, Lissette y otros. "Temas de derecho constitucional cubano" Editora Félix Varela. Cuba.2002.pp.11384 ALVAREZ TABIO, Fernando. "Comentarios a la Constitución Socialista”. Editora Ciencias Sociales. Cuba.1997.pp.124-125.

2 Documentos aprobados en la CUMBRE DE RIO DE JANEIRO, Brasil en el año 1992. Y los que posteriormente fueron discutidos y aprobados veinte años después en la propia sede por parte de los Estadistas que concurrieron a este conclave internacional, denominado Rio+20. Son coincidentes CAFERRATA, Néstor Alfredo. "Introducción al Derecho Ambiental". PNUMA. Elementos doctrinales acerca de la cultura ambiental. "Conferencia para la Protección del Globo". "Declaración de la Haya", bajo el lema: "El derecho a la vida, es la base de todos los demás derechos". Editora INE-SEMARNAT, México D.F 2004.pp.5-37. Son coincidentes ALENZA GARCÍA, Juan. "Manual de Derecho Ambiental". Universidad Pública de Navarra. España.2001.pp.739 Vid: DE BESA ANTUNES, Paulo. "Derecho Ambiental".ed. 14, Editora Lumen Juris. Brasil. 2010.p.3 BRAÑES BALLESTEROS, Raúl. "Manual de Derecho Ambiental".CITMA.Cuba.2000.p.3. CARABALLO MAQUEIRA, Leonel. "El Derecho Ambiental Cubano: Generalidades". 1era ed. Editora Félix Varela. Cuba.2000.pp.182. "Derecho y Medioambiente. Consideraciones generales. Respuesta de las ciencias juridicas a los problemas ambientales". Editora Pablo de la Torriente Brau. Cuba.2012.pp.11-32 FRANCO, Horacio. "Crítica a la concepción expansiva del Derecho Ambiental". Sobre la autonomía de esta nueva rama del derecho. Revista de Derecho Abeledo Perrot. No. 9 Argentina.2012. hptt// www.gerencia-ambiental.com pp.1-19 ABIDIN, Catalina y otros. "Derecho Ambiental su consideración desde la teoría general del derecho". Acerca de los fines del derecho ambiental. Revista Cartapacio de Derecho. Argentina.pp.1-25 ESTEVE PARDO, José: "Derecho del medio ambiente", 2a ed., Editora Marcial Pons. España. 2008. pp.11-149 FERNANDEZ, Tomás Ramón. “Grandeza y miseria del Derecho Ambiental." El Derecho Administrativo en el umbral del siglo XXI. Editora Tirant to Blanch. Universidad Complutense de Madrid. España. 2000. p.3423. en los derechos internos de cada país, como se constata en toda la región de Latinoamérica y en Cuba. ${ }^{3}$

En correspondencia al mandato internacional del que, en materia ambiental, el país es firmante, la organización de la Administración Central del Estado en la Ley No. 1323 de 1976 le atribuyó al Comité Estatal de Ciencia y Técnica el establecimiento, dirección y control del Sistema Nacional de Protección del Medio Ambiente y el Uso Racional de los Recursos Naturales, creándose la Comisión Nacional para la Protección del Medio Ambiente y el uso de los Recursos Naturales en Cuba. ${ }^{4}$

En 1980, el Decreto Ley No. 31 dictó las funciones del Comité Estatal de Ciencias y Técnica, delegadas a la Academia de Ciencias adscribiéndosele a ella la Comisión Nacional de Protección del Medio Ambiente y Conservación de los Recursos Naturales, bases que coadyuvaron a la aprobación de la Ley No. 33, hecho jurídico que permitió que Cuba por vez primera regulara en una ley esta materia como Estado parte de los Tratados internacionales del Derecho Ambiental Internacional, tal y como se señaló con anterioridad. ${ }^{5}$

3 El nuevo constitucionalismo en América Latina se deduce a la práctica democrática y a la participación ciudadana en los procesos de cada país. Nace a partir de la Constitución colombiana de 1991 y la Constitución de Ecuador de 1998, mostró avances en cuanto al reconocimiento de derechos ciudadanos y luego se da un cambio con la Constitución del 2008, que da al Estado ecuatoriano el carácter de constitucional de derecho. Venezuela 1999, da un proceso originario donde la Constitución nace a partir de la voluntad popular. Bolivia con su Constitución en el año 2009, encaminado a la creación de un Estado democrático, soberano y de participación popular. http:// www.pnuma.org. PNUMA.2013. Coincidentes con WOLKMER, Antonio Carlos. "Pluralismo Crítico y Nuevo Constitucionalismo en América Latina" 3a ed. Editora Alfa-Omega.Brasil.2010. QUIROLA SUÁREZ, Diana. "Sumak Kaway. Hacia un Nuevo Pacto Social en Armonía con la Naturaleza". El Buen Vivir: una vía para el desarrollo. Ediciones Abya-Yala, Ecuador. 2009. pp.7-79

4 Informe sobre la memoria del trabajo realizado por la COMARNA en torno al medio ambiente y los problemas ambientales de nuestro país dentro del período en que la misma ejercitó estas funciones a cargo del Estado Cubano. CITMA.

5 “Cumbre mundial medio ambiente". Brasil. La problemática ambiental que impera en el mundo y las principales acciones a realizar por los países que contaminan con mayor fuerza en pos de preservar al hombre. hptt/www.onu.org 1992. Coincidente con CARRILLO FUENTES, Juan Carlos. "Ciencia, ciudadanía y problemas ambientales. Empoderamiento de la Sociedad". Centro de Derecho Ambiental.México D.F.2004. hptt// www.iiciativadeacceso.org pp.1-7 "Estrategia mundial de la conservación". Brasil.1992. hptt/www.onu.org MATEO Ramón Martín, p.80 y ss. Luego varía su posición en T.III p.21 a partir de su utilización por Naciones Unidas y las Declaraciones de la Conferencia de Rio 92. "Tratado de Derecho Ambiental", Editora Trivium. España. 1991. BRAÑES BALLESTEROS, Raúl. "Informe 
En el inicio de la década del 90, del siglo pasado, se reorganizan los Organismos de la Administración Central del Estado (en adelante OACEs), cesando la Comisión Nacional de Protección al Medio Ambiente, atribuciones que fueron delegadas al Ministerio de Ciencias, Tecnología y Medio Ambiente (en adelante CITMA), quien dirige, ejecuta y controla la política del Estado y el Gobierno en esta esfera. Se deroga la Ley No. 33 por la Ley No. 81, quedando delimitadas en ella las facultades de los OACEs, de los Órganos Locales del Poder Popular, de la Fiscalía General de la República (FGR), y del Ministerio de la Agricultura (MINAGRI). Estos cambios unidos a legislaciones sustantivas que se han ido instrumentando en política tributaria, agraria, inversión extranjera, salud, protección e higiene, derecho administrativo sancionador, de energía y minas, hacen que hoy contemos con una adecuada normativa jurídica medioambiental que, a juicio de estos autores, no son excluyentes de una actualización que permita estar en mejores condiciones de dar un tratamiento a un nivel superior a los problemas ambientales que nos acontecen, en correspondencia con los resultados científicos, de los que las ciencias sociales no están ajenas, como se puntualiza en los Lineamientos del VI Congreso de Partido Comunista de Cuba para el modelo económico que se implementa. ${ }^{6}$

Los autores de esta investigación pretendemos contextualizar las acciones que se realizan en materia de control a los recursos naturales y su pertinencia en pos del desarrollo local, en cumplimiento a la carta magna, para el desarrollo sustentable. ${ }^{7}$ Toda vez que consideramos que la actual normativa ambiental no reconoce la

sobre el desarrollo del Derecho Ambiental Latinoamericano". Su aplicación después de diez años de la Conferencia de las Naciones Unidas sobre el Medio Ambiente y el Desarrollo. 2001. PNUMA "De Río a Johannesburgo. Perspectivas del Derecho Ambiental en Latinoamérica”, PNUMA, México D. F. 2002. pp.9-114

6 Lineamientos del partido comunista de Cuba, aprobados en el 6to Congreso, realizado en La Habana en el año 2012. Editora Política. Cuba.

7 Sustentabilidad ambiental. PNUMA. El desarrollo sostenible o sustentable, combinación de tres aspectos: crecimiento económico que favorezca el progreso y cohesión social y respete el medio ambiente, objetivos que al estar interrelacionados entre sí obligan a tratarlos de forma integrada. La necesidad de un enfoque integrado y estratégico de la dimensión social económica y ambiental del desarrollo. Valores con visión a largo plazo, la apertura en el diálogo con las partes interesadas, la integridad y responsabilidad social. hptt//www.pnuma. org. Coincide MORENO PLATA, Miguel. "Génesis, evolución y tendencias del paradigma del desarrollo sostenible". Editora Porrúa. México D.F. 2010. auditoría ambiental, la evaluación ambiental estratégica, ni las producciones más limpias como parte de los instrumentos de gestión, no contextualizando su actuación bajo las directrices que se implementaran por la Contraloría General de la República (en adelante CGR), relacionadas con el control ambiental y los servicios públicos en este caso los relacionados con la temática ambiental. ${ }^{8}$

\section{EL CONTROL AMBIENTAL EN CUBA. ANÁLISIS HISTÓRICO LEGISLATIVO}

El control ecológico aparece regulado en la Ley No. 81, relacionado con las herramientas de gestión ambiental y en particular con el ejercicio de la inspección estatal ambiental, ejercitada por el CITMA, ejecutada en los tres niveles en relación con lo regulado administrativamente para este tipo de acción ambiental a los recursos naturales en pos de preservar al bien jurídico ambiental. ${ }^{9}$

Como organismo rector de la política ambiental que por mandato se colige; consideran estos autores la existencia de una posible dualidad al control medioambiental; ante el mandato que la Ley No. 107 al concederle a la CGR, ejercitar acciones para proteger al medioambiente al más alto nivel, con normativas jurídicas en pos de alcanzar un derecho al desarrollo sustentable, de la sociedad presente y futura, con el auxilio de especialistas del CITMA y de otras áreas del saber que así se considere pertinentes cuando se ejercite este tipo de control a través de la auditoría ambiental. ${ }^{10}$

Ha permitido a estos autores considerar criterios vertidos sobre el tema por Traba Armada y Aguilera Mesa, quienes desde estudios científicos y prácticos han formulado presupuestos teóricos para su concreción en el país desde los saberes

8 Ley No. 107. Ley de la Contraloría General de la Republica de Cuba. 2013. hptt//www.contraloriageneral.cu p.6 Decreto No. 100, "De la Inspección Estatal", la Resolución No. 130 del CITMA, "Reglamento para la Inspección Ambiental Estatal", de fecha 1 de junio de 1995, la Resolución No. 103 del CITMA, "Reglamento de la inspección estatal de la actividad reguladora ambiental". Agencia del Medio Ambiente. CITMA. Cuba. 2007. Coincidente con FERNANDEZ RAMOS, Severiano. "Inspección Ambiental." Revista Derecho del Medio Ambiente y Administración Local. Universidad de Cádiz. España. pp.133-158.

9Ley No. 81, Ley del medio ambiente. República de Cuba. hptt// www.gacetaoficial.cu.

10Ley No. 107 de la Contraloría General de la República de Cuba. hptt//www.gacetaoficial.cu. Cuba. 
contable-administrativos acerca de la tutela de la auditoría ambiental, como mecanismo del control ambiental por parte de los servicios de la Administración Pública. ${ }^{11}$

Que de una manera u otra coadyuvarán a la recuperación económica, tributando a una base sólida en pos de avanzar en el establecimiento e implementación de la Estrategia Ambiental Nacional delimitando la problemática ambiental declarada por el CITMA, presupuestos que conducirán a un estadio superior en la protección del medio ambiente y el uso racional de los recursos naturales, teniendo en cuenta los limitados recursos financieros y materiales dispuestos por el Estado, que imponen como alternativa más viable su materialización gradual, siguiendo prioridades en estrecha vinculación con los problemas de desarrollo socioeconómico a nivel local, con una nueva mirada a través de la normativa tributaria, la que contribuirá a la creación de fondos dinerarios para mitigar la problemática ambiental declarada por el Estado,

11 ARMADA TRABAS, Dr.C. Elvira. Tesis Doctor en Ciencias Económicas. Metodología para desarrollar Auditorías de Gestión en Cuba. INTERAUDIT s.a. Cuba. 1997. Son coincidentes BOJÓROUEZ-TAPIA, Leonel y otros. "Aspectos metodológicos de la auditoría ambiental". PEMEX: ambientey energía. Retos del futuro. Serie E No. 69. UNAM. México D.F. 1998.pp.59-72 BELMONTE MARTIN, Ismael. "La ecoauditoría: un instrumento para la defensa del ambiente." Revista de la Facultad de Ciencias Sociales y Jurídicas de Elche. No. 4. España.2009.pp.57-78 DENEGRI DE DIOS, Fabiola Maribel. "La auditoría ambiental en las Pyme". La auditoría ambiental en la pequeña y mediana industria. Revista Contaduría y Administración. No. 235.Universidad de Baja California. México D.F.2011.pp.195-215 CONESA FERNÁNDEZ-VITORA, Vicente. "Auditorías medioambientales: guía metodológica". Editora MUNDI-PRENSA. España. 1997. pp.11-33. FERNÁNDEZ DE GATTA, Dionisio. "Principios del Derecho ambiental, la responsabilidad social corporativa en materia ambiental" vinculados a la práctica de la "auditoría ambiental". Boletín económico ICE. No. 2824. Universidad de Salamanca. España. 2004. pp.27-43. "Evaluación de los sistemas de ecogestión: la auditoría ambiental, análisis y régimen jurídico." Revista de Derecho Urbanístico y Medio Ambiente. $N^{\circ} 155$, 1997. España.pp.167-211. EGUSQUIZA PEREDA, Carlos. "Auditoría ambiental". UNAM. México D. F 2006. p.15 VIÑA VIZCAÍNO, Gerardo. "Bases conceptuales de auditoría ambiental como un instrumento de prevención de la contaminación." Colombia D.C. 2003. GONZÁLEZ MALAXECHEVARRÍA, Ángel. "La auditoría medioambiental, su evolución histórica y entorno político-institucional". La contabilidad, beneficios para el sector empresarial con la aplicación de las $P+L$ al disminuir costes. España.1997.p.2 GOMEZ GARCIA, Luis Eduardo. "Auditoría ambiental, voluntaria u obligatoria". La importancia de ejecutar la auditoría ambiental en la industria, beneficios. Revista Orden Público, Estado y Derecho. UNAM. México D.F.2011. pp.27-29 AGUILERA MESA, MSc. Ivvone. Tesis de Master en Contabilidad y Auditoría. Proyecto de Programas para la realización de auditorías de gestión ambiental. Contraloría General de la República de Cuba. Revista MAC, No. 12 de 2004. Cuba. al aplicar impuestos fiscales para su futura concreción (vertido ambiental). ${ }^{12}$

Cuba irradia como exponente de una política ambiental adecuada a tono con los nuevos paradigmas, en consecuencia con lo existente en el área jurídica medioambiental en Latinoamérica y Europa en materia de protección medioambiental. Cumple con sus deberes estipulados en los convenios de protección en que participa y es parte, creando políticas ambientales de protección ambiental dirigidas a garantizar el bienestar del hombre y de la comunidad en general, para el logro de una mejor gestión que facilite el desarrollo económico social sostenible, en atención a las limitaciones económicas como país bloqueado y al ser tributarias las acciones protectoras al medioambiente de recursos financieros suficientes, hoy no disponibles por la Administración Pública para su actuación. ${ }^{13}$

Es menester significar que nuestra ley marco en materia ambiental está necesitada de una actualización y evolución, apreciamos un desfase con lo que concurre en materia ambiental en el área de Latinoamérica y en otros bloques geográficos contrastados en cuestiones relacionadas con la contabilidad verde, el seguro ambiental, la justicia ambiental, la auditoría ambiental, el tratamiento a la responsabilidad ambiental en la norma adjetiva y sustantiva, como lo relacionado con el derecho administrativo sancionador y el desarrollo doctrinal del derecho administrativo ambiental. ${ }^{14}$

12 Estrategia ambiental nacional. 2010. Ministerio de Ciencias, Tecnología y Medio Ambiente. Cuba. hptt//www.medioambiente. co.cu.

13 TRIANA CORDOVÍ, Juan. "Un panorama de la economía cubana, las transformaciones en curso sus retos y perspectivas". DT No. 31.2008. hptt/ www.cienciassociales/weblog.com, consultado 14 de enero del 2014. pp.12 "La economía cubana: balance de las transformaciones y perspectivas". IX Encuentro Internacional sobre Comercio Exterior e Inversión Extranjera. Universidad de la Habana. (CDrom) Cuba. 2013. Cuba: ¿De la actualización del modelo económico al desarrollo? Revista Nueva Sociedad No 242. 2012. hptt//www.nuso.org pp.7-19

14VILLEGAS MORENO, José Luis. "Derecho Administrativo Ambiental". Editora Sin Límite CA. Venezuela.2009.p.545 Coinciden MORA RUIZ, Manuela. "Tendencias del derecho administrativo ambiental: análisis de legislación y jurisprudencia" Revista Derecho y Conocimiento. Vol. 2. Universidad de Huelva. España.2013. pp.419-436 "Tendencias del derecho administrativo. "El derecho administrativo ambiental: transformaciones en el derecho administrativo general" Revista Derecho y Conocimiento. Vol. 1. Universidad de Huelva. España pp.523-532 LOZANO CUTANDA, Blanca. "Derecho Ambiental Administrativo". 11na ed. Editora Trivium. España.pp.99-514. 
Esto se contextualiza en principios de la política ambiental cubana, donde se define que: el derecho a un medio ambiente sano es un derecho fundamental de todos los ciudadanos; la protección del medio ambiente es un deber ciudadano, la gestión ambiental es integral $\mathrm{y}$ transectorial y en ella participan de modo coordinado, los órganos y organismos estatales, otras entidades e instituciones, la sociedad y los ciudadanos en general, de acuerdo con sus respectivas competencias y capacidades. ${ }^{15}$

\subsection{Las herramientas de gestión ambiental, el control medioambiental a través de la auditoría y la inspección estatal}

Sus antecedentes, inicio y punto de partida están basados en los procesos tecnificados de la producción, acarreando la problemática ambiental hoy reconocida. Las imágenes de cientos de chimeneas arrojando humo representaron por mucho tiempo el símbolo del progreso y la consolidación del poder económico (Desde 1789, han sido muchos años de indiferencia ecológica y "violencia ecológica"). ${ }^{16}$

Es criterio de estos autores que hoy ya no existe esta percepción, el mundo y sus estadistas se han dado cuenta de que la protección al ambiente es una cuestión prioritaria a resolver y consolidar, que tendrá que funcionar con un nuevo pensamiento en las soluciones que se aborden por parte del Derecho Ambiental, hasta hoy no

15 Ley No. 81, disponible en hptt//www.gacetaoficial.cu 16 FERNANDEZ, Tomás Ramón. "Grandeza y miseria del Derecho Ambiental." El Derecho Administrativo en el umbral del siglo XXI. Editora Tirant to Blanch. Universidad Complutense de Madrid. España. 2000. p.3423. Son coincidentes CAFERRATA Néstor Alfredo. "Introducción al Derecho Ambiental". PNUMA. Elementos doctrinales acerca de la cultura ambiental. "Conferencia para la Protección del Globo". "Declaración de la Haya", bajo el lema: "El derecho a la vida, es la base de todos los demás derechos". Editora INE-SEMARNAT México D.F. 2004 pp.5-37. Son coincidentes ALENZA GARCIA, Juan. "Manual de Derecho Ambiental". Universidad Pública de Navarra. España.2001.pp.7-39 Vid: DE BESA ANTUNES, Paulo. "Derecho Ambiental". ed. 14, Editora Lumen Juris. Brasil. 2010.p.3 BRAÑES BALLESTEROS, Raúl. "Manual de Derecho Ambiental".CITMA. Cuba.2000.p.3. CARABALLO MAQUEIRA, Leonel. "El Derecho Ambiental Cubano: Generalidades". 1era ed. Editora Félix Varela. Cuba.2000.pp.1-82. "Derecho y Medioambiente. Consideraciones generales. Respuesta de las ciencias jurídicas a los problemas ambientales". Editora Pablo de la Torriente Brau. Cuba.2012. pp.11-32 SANTOS, Nicolás. "Los principios generales del derecho ambiental y la industrialización" Revista de Derecho. Universidad de Montevideo.Uruguay.2008. hptt//tradinco@adinet.com.uy pp.179-186. resueltas ante este período de crisis ambiental que coexiste. ${ }^{17}$

La auditoría es reconocida como función en evolución por todos los sectores de sociedades desarrolladas; si bien con limitaciones, impuestas por el influjo del entorno cultural, institucional y regulador en cada país, deduciéndose principios generales a fin de formar una base para el desarrollo de una teoría de aplicación general. Acción de control que se ha ocupado durante siglos del registro contable honrado y preciso de dinero y propiedades en asuntos estatales, en los servicios de organismos gubernamentales centrales, locales y misceláneos, en los asuntos de negocios de comerciantes, terratenientes, empresarios de riesgo, manufactureros y personas dedicadas a toda forma de empresa comercial e industrial, y en transacciones de otras instituciones y organizaciones grandes $\mathrm{y}$ pequeñas.

Su objeto es el cumplimiento de deberes por las personas responsables de la tutela y rendición de cuentas con respecto a la custodia de dinero y otros recursos, a la administración de haciendas, establecimientos de comercio y manufacturas, al suministro de servicios y a otras actividades. Para lograr que sea hecho con la competencia y autoridad necesarias para cumplir su objeto social, tanto el proceso de la auditoría como el acceso a la información deben ser por lo menos iguales a los de aquéllos que son auditados. Aunque se consiguen otros beneficios de la auditoría, el principal es el informe y la opinión de los auditores como resultado de la investigación. ${ }^{18}$

Este control ecológico o ambiental es instrumentado en las normas técnicas ISO 14000, ${ }^{19}$

17 Véase los sucesos acaecidos sobre la Revolución Industrial en Inglaterra y su incidencia desde esa época en la agresión al medioambiente, con mayor énfasis en los adelantos científico técnicos generados por el hombre, que a partir de este suceso histórico intensificaron más los adversos ambientales. hptt/ www. wikipedia. Consultada el 20 de junio del 2010.

18 Auditoría ambiental, como actividad de control. Ley No. 107. Ley de la Contraloría General de la República de Cuba. 2013. hptt//www.contraloriageneral.cu

19 Normas ISO 14001:1998 Sistemas de gestión ambiental. Especificación y directrices para su uso. Organización Mundial no gubernamental, elabora y aplica los patrones internacionales de calidad; certifican empresas de los sectores comercial, industrial y tecnológico.hptt//www.iso.org p.17 Normas ISO 14001. Implementa el procedimiento de la auditoría ambiental. SGMA: Especificaciones y guías de uso. ISO 14004. SGMA: Directivas generales sobre principios, sistemas y técnicas de apoyo. ISO 14010. Pautas para Auditoría Ambiental: 
definiendo medioambiente - son normas técnicas del sistema de gestión ambiental, como estructura organizativa, actividades de planificación, responsabilidades, prácticas, procedimientos, procesos y recursos para desarrollar, implementar, realizar, revisar y mantener la política ambiental, diagnosticando la problemática ambiental con un carácter multidisciplinario, interdisciplinario y transdisciplinario, estableciendo el nivel de responsabilidades, apoyada en la legislación y políticas vigentes, partiendo de un proceso de toma de decisiones y de la participación ciudadana, relacionado con el impacto ambiental, produciendo una determinada acción sobre el medioambiente; vinculada a la auditoría ambiental, como proceso de verificación sistemático y documentado, para obtener y evaluar objetivamente la evidencia de las actividades, incidentes, condiciones y sistemas de gestión ambiental especificados o la información que sobre estos temas cumplen con los criterios del control, realizado por el CITMA a través de la inspección estatal, a tenor de la Ley No. 81 y las normas administrativas sustantivas. ${ }^{20}$

Le corresponderá a la CGR, ejercitar la más alta tutela al control medioambiental, a través de programas de auditoría (directrices) ${ }^{21}$, como un servicio público de la Administración Estatal, que parte del reconocimiento que tiene el medioambiente desde el derecho constitucional, aún no desligado de la función administrativa que se ejercitaba por el extinto Ministerio de Auditoría y Control a través del Control gubernamental a los OACEs.

Actividad en correspondencia con la Evaluación del Impacto Ambiental, por ser este el fin de la auditoria ambiental, relacionada con

Principios generales. ISO 14011. Pautas para Auditoría Ambiental: Procedimientos. ISO 14012. Pautas para Auditoría Ambiental: Criterios de calificación de auditores ambientales. ISO 19011. Fundamentos de la Auditoría Ambiental. ISO 14020 a 14025. Ecoetiqueta ambiental ISO 14034. Indicadores de desempeño Ambiental ISO 14040 a 14049. Análisis del ciclo de vida ISO 14050. Vocabulario ISO 14062. Ecodiseño ISO 14064. Gases efecto invernadero hptt/www.iso.org Coinciden MENDEZ ORTIZ, Luis. "Normas ISO 14000 como instrumento de gestión ambiental empresarial". Universidad Veracruzana. México D. F. 2009. p.75 HERRERIAS ARISTI, Eduardo. "Relación de las ISO 14000 y la auditoría ambiental”. México D.F. 2009.

20 Inspección ambiental, Ley No. 81, Ley del medio ambiente. República de Cuba. hptt// www.gacetaoficial.cu.

21 "Directrices de la auditoría ambiental". En relación a la Ley No. 107 para su ejecución en el país. hptt//www.contraloria.cu. p.12 las tecnologías utilizadas por el empresariado cubano, - actualmente no limpias por la obsolescencia industrial y heterogeneidad de más de 50 años - y cómo evitar o prevenir estos impactos, tributarios a un adecuado equilibrio ecológico como situación esperada, con el auxilio del CITMA, quien deberá insertarse en la ejecución de este control ambiental con la ejecución de la auditoría. ${ }^{22}$

El CITMA, OACE ejecuta el control al medio ambiente a través de la Inspección Estatal, amparada en la Ley No. 81, y en las normas sustantivas que la contextualizan en el orden administrativo a través del control gubernamental, utilizando para ello las normas técnicas ISO en el control al medioambiente como lo hace la CGR, ejercitada por sus tres niveles en todo el territorio nacional, en atención al programa diseñado, en correspondencia con los principales problemas medioambientales que tengan mayor preponderancia recogido en la Estrategia Ambiental Nacional. Acciones vinculadas con la aplicación de las herramientas de gestión ambiental como una política pública, en muchas ocasiones cumpliendo lo establecido en materia de control Gubernamental. ${ }^{23}$

22 DUGUIT, León. "Las transformaciones del Derecho Público", Editora Colin, 3a ed. París, 1925, p. 51. Actividad cuyo cumplimiento debe de ser regulado, asegurado y fiscalizado por los gobernantes, es indispensable a la realización y al desenvolvimiento de la interdependencia social, de tal naturaleza que no puede ser asegurado completamente más que por la intervención de la fuerza gobernante. Son coincidentes GARCIA DE ENTERRIA, Eduardo y otros. "Curso de derecho administrativo". Editora Marcial Pons. España.2003. "La actividad industrial y mercantil de los municipios", Revista de Administración Pública, No.17, 1955. GARRIDO FALLA, Fernando. "El concepto de servicio público en el derecho español" Universidad Complutense de Madrid, Revista de Administración Pública No.135.1994. p.8 Toda actividad técnica realizada de manera continua, regular y uniforme, tutelada por la Administración Pública y gestionada directamente por esta o indirectamente por sujetos independientes autorizados para ello, bajo un régimen jurídico especial y destinado a la satisfacción de un interés general. TOLEDO TOLEDO, Dalia. Tesis maestría: "La calidad en los servicios públicos como una estrategia para legitimar a los gobiernos locales". Universidad del Ismo. México D.F. (2008). LONGO, Francisco. "La nueva gestión pública en la reforma del núcleo estratégico del gobierno: experiencias latinoamericanas". Nueva Gestión Pública y regulación en América Latina. CLAD 2001.pp.8-73 CALLAFEL, Jorge. "Los servicios públicos". Editora Anuario Jurídico. Argentina.2007.pp.1-19

23 GAGO, Ángel. "La reforma fiscal verde. Teoría y práctica de los impuestos ambientales." Universidad de Madrid. España.1999. p.56 Son coincidentes BOKOBO MOICHE, Salvador. "Gravámenes e incentivos fiscales ambientales". Revista Trivium. España. 2000. pp.5-47 DÍAZ ARAUJO, Mercedes. "Derecho Ambiental. Poder de policía". La regulación ambiental: nuevas formas de intervención preventiva, represiva, compensatoria y estimuladora. Revista Doctrina-Jurisprudencia.Argentina.2012.pp.1-20 GARCIA-ARIAS, Juan. "Un nuevo marco de análisis para los bienes públicos: la 
En este participan equipos multidisciplinarios de otros OACEs, es el caso de la inspección forestal del Ministerio de la Agricultura, de la inspección sanitaria del Ministerio de Salud Pública, de la inspección sobre seguridad y salud laboral del Ministerio de Trabajo y Seguridad Social y del Ministerio del Interior, entre algunos de los organismos vinculados a la actividad de la inspección estatal. Participan en esta acción de control medioambiental de conjunto con el CITMA como especialistas certificando las conclusiones a que arriban en sus evaluaciones. ${ }^{24}$

teoría de los bienes públicos globales" Transformación sustantiva en la justificación y capacidad de actuación del sector público en la economía de mercado. Revista Estudios de Economía Aplicada. Volumen No.22. Universidad de León. España. 2004.pp.187-212. TERAN CONTRERAS, Juan y otros. "Instrumentos fiscales de la gestión ambiental". Políticas de control de la contaminación ambiental, el sistema de regulaciones, la reducción de los índices contaminantes, el establecimiento de estándares ambientales y la aplicación de sanciones. Revista Estudios de Economía Aplicada. Volumen No.29. Universidad de León. España. 2009. pp.1-12 IBARRARÁN VINIEGRA, María. "Externalidades, Bienes Públicos y Medio Ambiente". Universidad de las Américas. México D.F. 2010.pp.1-15 ARIAS MENDOZA, Jhon Jairo. "Bienes y servicios ambientales". Mercado de los bienes y servicios ambientales, una de las estrategias más adecuadas para alcanzar objetivos de conservación y desarrollo sostenible. Brasil.1992. Vinculado a la economía ambiental, al definirse los "Bienes Ambientales" como: los recursos tangibles utilizados por el ser humano como insumos en la producción o en el consumo final y que se gastan y transforman en el proceso, como madera, frutos, pieles, carne semillas, medicinas, entre otros que son utilizados por el ser humano para su consumo o comercialización. Revista Estudios de Economía Aplicada. España. 2010. pp.1-9 GARRIDO VAZOUEZ Raúl. "Estudio de caso: Cuba. Aplicación de instrumentos económicos en la política y la gestión ambiental". Anuario Facultad de Ciencias Económicas y Empresariales.pp.33-40. Cuba.2011 GARCINI GUERRA, Héctor. "Derecho Administrativo" fomento: como estímulo y apoyo conferido por la Administración Pública.Editora Pueblo y Educación.Cuba.1981.pp.174 POLO MACEIRAS, Elena. Tesis doctoral: "Un sistema tributario, de la realidad a la aspiración", la tributación ambiental vinculada al impuesto sobre el vertido ambiental. Universidad de Oriente. Cuba. (2010). REGUEIRO ALE, Vladimir. "La Legislación tributaria en Cuba", el cumplimiento de la política tributaria desde su perspectiva de experto en la ONAT dentro del Ministerio de Finanzas y Precios. Cuba. BONELL COLMENERO, Ramón. "La tributación ambiental y el Protocolo de Kyoto". GAGO, Alberto y otros. "Impuestos ambientales y reformas fiscales verdes" La configuración de las políticas ambientales y tributarias. Revista Economía. No. 4. p.91 Universidad de Vigo. España.2010. ALARCÓN GARCÍA, Gloria. ¿Son los tributos ambientales una opción para la financiación de las HHPP? Revista CUIDES España.2012.pp.201-251 BUÑUEL GONZÁLEZ Manuel. "Marco General de la Tributación medioambiental: concepto, justificación y base imponible”. En Tributación medioambiental: teoría, práctica y propuestas. Editora Deloitte-Thomson-Civitas. España. pp.41-58. PUIG VENTOSA, Ismael y otros. "La efectividad de los impuestos ambientales sobre el vertido y la incineración de residuos existentes en España." Documentos del IEFDOC 9. España. 2012.pp.57-79 FERRÉ OLIVE, Edgardo. "Legislación ambiental y política tributaria". Editora CECONTA. Argentina. 2010.pp.1-24 VARGAS DELGADO, Iris. "Tributos ambientales para la protección de la atmósfera". Contraloría General de la República de Chile. 2007.pp.1-5

24 Ley No 81, la responsabilidad civil, penal y administrativa,
Acciones consideradas por estos autores, tanto la de la inspección como la de la auditoría tienen una respuesta adecuada a la protección del bien jurídico ambiental, con la exigencia de los tipos de responsabilidad ambiental, aplicada en sus tres aristas: la civil, la penal y la administrativa; esta última la mayormente utilizada por los controladores en el ejercicio como función pública estatal $^{25}$ al aplicársele la responsabilidad objetiva, aún no establecida de forma adecuada en nuestro ordenamiento jurídico en torno a la materia procesal. $^{26}$

\subsection{Tendencias actuales relacionadas con la tutela ambiental en relación a la protección del medioambiente y el control ambiental en el derecho comparado}

La rápida evolución de la problemática medioambiental y de los conceptos sobre los que se asientan las políticas ambientales, así como los problemas que han sido necesarios enfrentar por el hombre como ser social, han acabado por convertir en naturales los procesos de transformación institucional que han tenido lugar en los últimos años y que podrán ocurrir en el futuro. Estas transformaciones no se refieren sólo a las estructuras orgánicas de las instituciones de la Administración sino también a todos los mecanismos de articulación entre el Estado y la sociedad civil.

el derecho sustantivo cubano por los organismos de la Administración Pública, tratamiento. hptt/www.gacetaoficial. $\mathrm{cu}$ Coincide ARNER GUERRE, Ángel. "Responsabilización voluntaria de la industria en la protección medio ambiental". En cumplimiento del Libro Blanco y el Libro Verde de la Unión Europea. Universidad de Zaragoza. España. 2013. pp.123-342

25 Vid: Ley No. 81, Ley del medio ambiente. República de Cuba. hptt// www.gacetaoficial.cu.

26 MORENO MEDINA, Ángel. "Responsabilidad patrimonial por daño ambiental: propuestas para una reforma". La comisión del daño ambiental, políticas regulatorias en el ordenamiento jurídico por la practica de la auditoría ambiental. Universidad Carlos III. España.2007.p.13 Coincidente con JAQUENOD DE ZOGON, Silvia. "El derecho ambiental y sus principios rectores".p.372. Editora Dikynson. España.2009. VILLEGAS MORENO, José Luis. "Aproximación a la configuración del Derecho Administrativo Ambiental en Venezuela". Editora Sin Límite.2009. Venezuela.p.45 OBREGON SANCHEZ, Carolina. "La responsabilidad ambiental de las empresas". Revista Administración. Colombia.2012. hptt//www.revista.MMM. org p.28 LOZANO CUTANDA, Blanca. "Derecho Ambiental Administrativo". 4a ed. Editora Dykinson. España. 2001. pp.9-137 ARNER GUERRE, Ángel. "Responsabilización voluntaria de la industria en la protección medio ambiental". En cumplimiento del Libro Blanco y el Libro Verde de la Unión Europea. Universidad de Zaragoza. España. 2013. pp.123-342 
Para distinguir la auditoría ambiental de otros servicios, consultamos la definición de auditoría, dada por la Asociación Americana de Contabilidad: "proceso sistemático para obtener y evaluar objetivamente evidencia con relación a una afirmación verificable acerca de actividades y eventos para cerciorarse del grado de correspondencia entre la afirmación y los criterios establecidos y luego comunicar los resultados a los usuarios interesados" 27

La Cámara Internacional de Comercio, define la ecoauditoría como:

(...) herramienta de gestión que comprende una evaluación sistemática, documentada, periódica y objetiva del funcionamiento de la organización ambiental. Prevé la implantación de gestión, así como los equipos de control necesarios con objeto de: Facilitar el control de gestión de las prácticas medioambientales y declarar el cumplimiento de la política de la compañía de acuerdo con la normativa medioambiental. ${ }^{28}$

Este concepto, se introduce por vez primera en los Estados Unidos, en respuesta a la legislación ambiental cada vez más restrictiva y a las pesadas penas asociadas a las infracciones de manera voluntaria. En una primera fase los objetivos consistían en asegurar que la empresa cumpliera de forma metódica y global las disposiciones legales. Disposición preventiva que evolucionó en la década de los ochenta del pasado siglo hacia una posición defensiva, y así comenzaron a ser vistas como instrumentos capaces de promover una utilización inmejorable de los recursos, permitiendo mejorar la imagen de la empresa en el mercado y contribuir a su competitividad. ${ }^{29}$

27 ANTUNEZ SÁNCHEZ, Alcides. Tesis de Especialidad. 2005. Facultad de Derecho. Cuba. Se hace reseña de las herramientas de gestión, con el uso de la auditoria ambiental. Revista EUMENED. España.

28 Vid: Auditoría ambiental. Ley No. 107. Ley de la Contraloría General de la República de Cuba. 2013. hptt//www. contraloriageneral.cu

29 Etiqueta ecológica", MERCOSUR, 2003. "Etiquetas verdes", p.91, Series normas técnicas ISO 9000-14000.2000. hptt//www. iso.org Pacto Global de las Naciones Unidas para contribuir a la emergencia de "valores y principios compartidos que den una cara humana al mercado global". Los participantes ingresan voluntariamente y provee un marco general para fomentar el crecimiento sustentable y la responsabilidad cívica de empresas comprometidas. Posee enfoque preventivo frente a los retos medioambientales, promueve mayor responsabilidad ambiental, alienta el desarrollo y la difusión de tecnologías limpias. http:// www.pactoglobal.org.ar/content.Consultado 15 agosto 2010. Coincide LOZANO CUTANDA, Blanca y otros. "La nueva etiqueta
A finales de los años setenta del pasado siglo, cuando una serie de empresas implantaron programas de auditoría, llegando a utilizar Auditorías Ambientales de Seguridad e Higiene (en adelante EHS) para analizar el cumplimiento de las normas gubernamentales y las normas internas. $^{30}$ Concluyendo los ochenta surgió un tercer factor relacionado con el desarrollo de auditorías EHS que traducía el deseo creciente de la opinión pública de que las empresas prestasen una información completa sobre su incidencia y actuación sobre el medioambiente. En los últimos años las empresas químicas, petrolíferas e industriales han ido intentando responder con la publicación de informes medioambientales públicos. En la actualidad se discute entre los profesionales que ejecutan el control ambiental, en torno a los objetivos y estrategias destinados a prestar información sobre el grado de cumplimiento de las normas sobre medioambiente y sobre sus riesgos.

La Agencia de Protección Ambiental de Estados Unidos, consideró obligatoria la implantación de auditorías medioambientales independientes, fue a partir de ahí cuando las normas norteamericanas comenzaron a exigirles a las empresas la publicación de algunos datos. (Superfund Amendments and Reauthorization Act (SARA), Título III, Sec. 313, obliga a que las empresas informen sobre las cantidades de sustancias tóxicas que emiten). En la Unión Europea, las normas ambientales que una empresa debe cumplir varían considerablemente según el país de implantación.

ecológica de la Unión Europea”. Revista Interdisciplinar de Gestión Ambiental No. 2001. España. p.5

30 HARRISON Y MAUTZ, sobre la Filosofía de la Auditoria, sentaron pautas desde la teoría de la auditoria, en la introducción a sus propuestas sobre postulados de auditoría Mautz y Sharaf (1961) citan de Aristóteles ("Los Trece Libros de los Elementos de Euclides", traducido por Sir Thomas H. Heath, vol. 1, segunda edición, Pág 119): "Toda ciencia demostrativa debe partir de principios no demostrables, o de lo contrario los pasos de demostración serían interminables". Cuestiones presentes al ejercitar la auditoría, como acción de control de la Administración Pública en relación con su patrimonio. Si bien el propósito primordial de los postulados es establecer una base para la formulación de teoría, también describen ellos las características intrínsecas de la auditoría y definen un modelo con el cual se pueden comparar potenciales situaciones de auditoría. Ya que producirá un beneficio económico o social. La expectativa de la sociedad en relación con la auditoría y las circunstancias en que ha aparecido el fenómeno de la auditoría demuestran sin lugar a duda que una característica definitiva del proceso de auditoría es la de que debe ser independiente en todo sentido de la organización y los miembros de la organización sometidos a la auditoría. 
El Reglamento de la Comunidad de Estados Europeos 1836/93, aplicado a partir de abril de 1995 , trata de atenuar las referidas diferencias, establece normas de gestión medioambiental, exige que las empresas promuevan la realización de auditorías medioambientales y que elaboren informes ambientales para el gobierno de su país, y éste, a su vez, proceda a su divulgación. ${ }^{31}$

Considera un vasto conjunto de temas ambientales, entre los que se incluyen la emisión de contaminantes, la producción de residuos, el ruido y consumo de materias primas, el consumo de energía y del agua. Hoy toda la gestión medioambiental se transforma, las empresas acabarán por constituir una función independiente que tendrá que repartir sus prioridades con otros procesos, hasta convertirse en una función cada vez más integrada en estos. Un cuarto factor hoy se visualiza con la creciente confianza de los directivos en la utilidad de esta disciplina como instrumento de medida que valora y ayuda a cambiar y a mejorar la actuación EHS, cerrando así un ciclo completo en relación al tratamiento que se le da a esta institución. ${ }^{32}$

Estos autores estiman que fue la industria la primera que sintió la necesidad de prever los aspectos ambientales de sus operaciones y ahora es también ella la que espera que la auditoría desempeñe un papel importante en la próxima fase de la gestión medioambiental.

31 Libro verde. Fomenta un marco para la Responsabilidad Social de las Empresas. Se manifiesta en una responsabilidad interna, incluye aspectos de gestión de recursos humanos, salud y seguridad en el trabajo, adaptaciones a los cambios y gestión del impacto ambiental y de los recursos naturales. La disminución de contaminaciones, del consumo de recursos naturales, de los gastos energéticos o de la generación de residuos para aumentar la rentabilidad y competitividad. Bruselas. 2001.pp.1-35 Libro Blanco, incrementa la protección a la salud humana y al medio ambiente, frente a las exposiciones de sustancias y preparados químicos, mejora la competitividad, la capacidad de innovación del sector químico, en cumplimiento del principio de cautela. 2001. Manual para la formación en medio ambiente. Editora Lex Nova. España. 2008.

32 BERNAL PEDRAZA, Ángel. "Responsabilidad ambiental de las empresas, un compromiso ético con el desarrollo sostenible". Universidad de Colombia.2009.p.23 . Son coincidentes BELMONTE MARTIN, Ismael. "La ecoauditoría: un instrumento para la defensa del ambiente." Revista de la Facultad de Ciencias Sociales y Jurídicas de Elche. No. 4. España.2009.pp.57-78 Coincide PNUMA. 2012. Temas emergentes: en nuestro medio ambiente mundial. http://www.unep.org/yearbook/2012/ pdfs/ UYB_2012_FULLREPORT_spanish.pdf ARNER GUERRE, Ángel. "Responsabilización voluntaria de la industria en la protección medio ambiental". En cumplimiento del Libro Blanco y el Libro Verde de la Unión Europea. Universidad de Zaragoza. España. 2013. pp.123-342
Esto se confirma con los resultados de investigadores desde el área contable-financiera de países consultados de la Unión Europea y Latinoamérica, como Gaz, Casals, Malheiros, Eyer, Iribarrem, Malaxechavarría, Dense Pinheiro, y Garay, al definirla como: "proceso de investigación realizado por un auditor independiente dirigido a determinar el grado de eficiencia empresarial, con relación al grado de satisfacción experimentado por la comunidad y su hábitat, señalado en su informe de auditoría a los agentes degradantes del medio ambiente y la magnitud de la degradación producida", además de una "investigación sistemática, ejecutada por especialistas, destinada al sistema de gestión ambiental y sus resultados. ${ }^{33}$

Otros autores contrastados desde los saberes jurídicos de los países consultados en materia de derecho comparado, como: Carmona Lara ${ }^{34}$, De Bessa Antunes ${ }^{35}$, Irribarren ${ }^{36}$, Bustamante Alsina ${ }^{37}$,

33 Gestión ambiental, Ley No. 81, Ley del medio ambiente. República de Cuba. hptt// www.gacetaoficial.cu.

34 CARMONA LARA, Dra. Maria del Carmen. Sobre los aspectos jurídicos de la auditoría ambiental en México. La autora hace un análisis jurídico de los aspectos de esta acción de control al medioambiente dentro de su país.

35 DE BESSA ANTUNES, Dr. Paulo. Direito ambiental. Editora Lumen Juris LTD. 12 edición. ISBN 978- 85-375-0616-5. 2011. Brasil. El autor ejecuta un análisis sobre la teoría general del Derecho Ambiental. El orden constitucional del medio ambiente. Las competencias constitucionales en materia ambiental. La política y el sistema nacional del medioambiente. El poder de la policía ambiental. Saneamiento ambiental. Responsabilidad ambiental. Educación Ambiental. Con la Evaluación del Impacto Ambiental. El medio ambiente urbano. La protección legal a la diversidad biológica. La política energética y el medio ambiente. Vinculados con el Derecho Administrativo Ambiental.

36 IRRIBARREN, Dr. Federico, "Evaluación de impacto ambiental. Su enfoque jurídico", pág. 43, Editora Universo, 1997. El autor refiere sobre la auditoría ambiental: tiene por objeto apreciar el impacto que todo o parte de la producción o existencia de una empresa es susceptible de generar sobre el ambiente. Puede tener un objeto de alcance variable.- Puede limitarse su objeto al impacto de un producto o línea de producción. Puede tratarse de un análisis de riesgos presentados por ciertos productos o materias primas, o su producción susceptible de generar tal o cual desecho.- También puede tener por objeto analizar los efectos de un establecimiento industrial en un lugar determinado.-La auditoria tomará en consideración la situación geográfica, económica, sociológica e hidrológica para apreciar las incidencias que el proyecto de implantación sería susceptible de generar en esos medios. Finalmente la auditoría ambiental podrá tener por objeto general, enfocando un análisis global del impacto ambiental que producirá el funcionamiento de un establecimiento en el lugar.

37 BUSTAMANTE ALSINA, Jorge: "Derecho Ambiental. Fundamentación y normativa" pág 98 a 101, Editora Abeledo Perrot, 1995 refiere que la auditoría ambiental debe realizarse mientras la empresa permanezca activa; el estudio de impacto es previo y está destinado a obtener una autorización administrativa - tiene un objetivo diferente, apunta a informar a la dirección de la empresa sobre los riesgos que puede correr y la consecuente responsabilidad que pueden generarles y así poder 
Fernández de Gatta Sanchez ${ }^{38}$, Di Trindade Arnado ${ }^{39}$, De Medeiros Garcia ${ }^{40}$, Beltrao $^{41}$, Martin 42, Meier ${ }^{43}$, Bustamante Alsina ${ }^{44}$,Lopez Sela y Ferro Negrete $^{45}$, Quintana Valtierra ${ }^{46}$, Morales

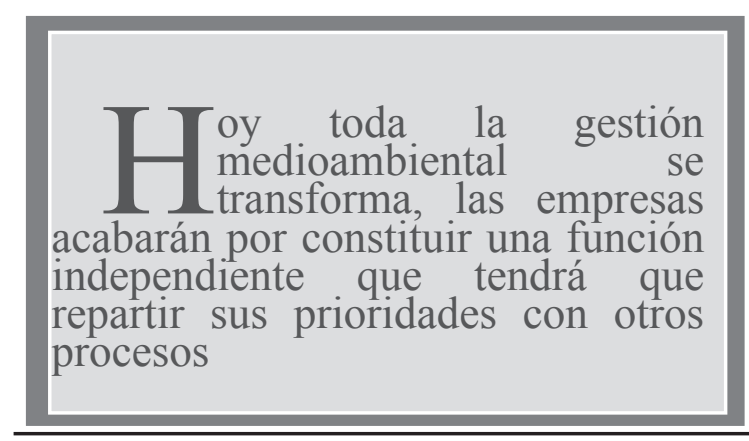

preverlos, minimizarlos y evaluarlos.

38 DE GATTA SANCHEZ, Dionisio. Universidad de Salamanca. España, señala los aspectos generales sobre la protección jurídica del medio ambiente, sobre las actividades relacionadas con el derecho administrativo y el control al medio ambiente, con pertinencia en la responsabilidad ambiental.

39 DI TRINDADE ARNADO, Frederico A. Direito Ambiental Esquematizado, el ejercicio de la auditoría ambiental y sus presupuestos jurídicos. Editora METODO, Brasil, 2011.

40 DE MEDEIROS GARCIA, Leonardo. el derecho ambiental constitucional, Brasil. 2010, Editora JIUS POVIVM

41 BELTRAO, F. G. Direito Ambiental, 2011.Brasil.

42 MARTIN, Dr. Leandro Maximiliano. Apuntes del Derecho Ambiental, hace un estudio sobre este nuevo derecho, en relación a su problemática, conceptualización por diversos autores como rama del derecho, la evolución de la conciencia ambiental en relación con la problemática ambiental internacional, desde sus orígenes históricos remotos, el vocabulario ambiental, la legislación ambiental, la ecología el daño ambiental, el cambio climático, la relación del hombre con el ambiente, el biocentrismo jurídico, los modelos de desarrollo, el desarrollo sustentable, y la tutela jurídica del medioambiente.

43 MEIER, Dr. Henrique. Profesor de politología y derecho administrativo, realiza un estudio sobre las relaciones entre el derecho y el medio ambiente, aborda temas como la industrialización, urbanización, latifundio, el concepto de derecho ambiental, las funciones de esta rama del derecho dentro de la sociedad, los factores que intervienen en esta rama del derecho con el Estado en sus relaciones, y su conclusión al denominarle el Derecho que ha de asegurar la vida en el planeta, con su nicho de investigación en la actual Republica Bolivariana de Venezuela. Publicado en el 2007.

44 BUSTAMANTE ALSINA, Dr. Jorge. Aspectos relacionados con el medio ambiente, su preocupación a escala global, la difusión necesaria de la conciencia global en la materia tratada, la necesidad de su institucionalización en materia de protección, los conclaves internacionales realizados en relación al derecho del medio ambiente de mayor relevancia que han trazado pautas, el poder de policía de la Administración Pública, la intervención de la Administración Pública y la tutela ambiental, las regulaciones administrativas, la Auditoria Ambiental, la EIA, 2010.

45 LOPEZ SELA Dr. Pedro, Universidad Autónoma de México. estudio de las implicancias del Derecho Ambiental, relacionado con el derecho, la ecología y el medio ambiente, la gestión ambiental, la AUDITORIA AMBIENTAL, responsabilidad jurídica por daños al medioambiente..

46 QUINTANA VALTIERRA, Dr. Jesús. Derecho Ambiental Mexicano, Lineamientos generales, 2006. editora Porrúa. 1era edición.
Lamberti $^{47}$, Lorenzetii ${ }^{48}$, Bustamante Alsina ${ }^{49}$, Morales Lamberti ${ }^{50}$, Novak $^{51}$, y Sales ${ }^{52}$, coinciden en señalar que entre los modos de actuación de la Administración Pública, esta acción de control es una actividad de limitación o policía, es una prestación de un servicio público, una actividad de gestión o económica, con la inspección y la potestad sancionadora o de policía desde la perspectiva que asumen las Administraciones Públicas, de sus funcionarios ante sus faltas y por cometer daños a los recursos naturales, con el consabido incumplimiento de las políticas ambientales implementadas en pos del desarrollo sostenible o sustentable.

En Cuba, las investigaciones realizadas por especialistas del área contable financiera, como Armada Traba ${ }^{53}$, Font Aranda ${ }^{54}$, Pelegrin Mesa ${ }^{55}$,

47 MORALES LAMBERTI, Dra. Alicia. Gestión y Remediación de Pasivos Ambientales: políticas y atribución de responsabilidad, editora MULTIGRAF, en Argentina en el año 2008. hace un abordaje sobre los pasivos ambientales y su configuración jurídica, en relación con la actividad minera. La actividad de policía ambiental, el seguro ambiental, el control y la fiscalización ambiental, y las concesiones administrativas ambientales.

48 LORENZETII, Dr. Ricardo Luis. Teoría del Derecho Ambiental, sobre el origen de esta nueva rama del derecho, paradigmas teóricos, el seguro ambiental, la seguridad jurídica ambiental, la tributación verde, las técnicas de comando y control, la normativa ambiental argentina análisis de sentencias internacional ambientales, el paradigma ambiental, incertidumbre y riesgos ambientales. 2008

49 BUSTAMANTE ALSINA, Dr. Jorge. Fundamentación normativa del Derecho Ambiental. Editora Abeledo Perrot. Argentina. Aborda la temática del control al medio ambiente a través de la auditoria ejecutada por la Administración Pública. La diferencia y analogía con la EIA. 2011.

50 MORALES LAMBERTI, Dra. Alicia y autores. UNIVERSIDAD NACIONAL DE CÓRDOVA. Argentina. El control ambiental en la actividad de la minería y su importancia en preservar los recursos naturales. 2008, Editora ALVERONI.

51 NOVAK, Dr. Frank. Diplomado en Derecho Ambiental y procesos ambientales. UNIVERSIDAD LA SALLE. CEJA. México.

52 SALES, Dr. Rodrigo. La Auditoría ambiental, aspectos jurídicos. Sao Paulo. Brasil. 2001. Aspectos jurídicos para la concreción de esta herramienta de gestión.

53 Profesora del área de las ciencias contables en la UNIVERSIDAD DE LA HABANA, investigadora en la temática relacionada con la Auditoría ambiental, realizando aportes desde la arista contable financiera, en relación con la tutela y el ejercicio de esta institución jurídica. Cuba.

54 Ilustre profesora del área de las ciencias contables de la UNIVERSIDAD DE MATANZAS, quien desde el Centro de Estudios del Desarrollo para el Turismo, ha desarrollado en investigaciones la pertinencia de esta herramienta de gestión ambiental en pos de un desarrollo sustentable. Cuba.

55 Profesor destacado en el área contable financiera en la UNIVERSIDAD DE CAMAGÜEY, quien en su autoría y coautoría ha venido desarrollando estudios sobre la temática de la tesis en el centro de estudios dentro de su área académica, sobre la pertinencia de la aplicación de este herramienta de gestión en el sector empresarial y del turismo en el país. Cuba. 
Pérez Bello ${ }^{56}$ y Aguilera Mesa ${ }^{57}$, quienes desde esta arista han demostrado insuficiencias en la consecución de esta herramienta de gestión relacionada con la contabilidad verde, la falta de cultura ambiental, la no exigencia de la responsabilidad ambiental, la reparación del daño ambiental y su relación con los costes ambientales, la falta de un seguro ambiental obligatorio que permita la indemnización de los perjuicios que se ocasionen ante daños al ambiente. Otros académicos cubanos, que desde las ciencias jurídicas, han investigado sobre el tema, son: Viamontes Guilbeaux ${ }^{58}$, Caraballo Maqueira ${ }^{59}$, Rubio-Legrá6 ${ }^{60}$, Rey Santos ${ }^{61}$, Fournier Duharte ${ }^{62}$, Monzón Brugera ${ }^{63}$, Elías Vega ${ }^{64}$, y Cánovas González ${ }^{65}$, entre otros; realizando aportes al Derecho del Medio Ambiente, relacionados con la protección medioambiental, la tutela de la

56 Profesor e investigador en el área contable financiera en la Facultad de Ciencias Empresariales y Económicas, en la UNIVERSIDAD DE GRANMA, ha desarrollado estudios sobre el desarrollo de la auditoría ambiental en el territorio de la provincia. Cuba.

57 Directiva de la Contraloría General de la República, quien ha desarrollado investigaciones relacionadas con el control a ambiente, y en especial lo relacionado con la auditoria, la misma trabaja actualmente en lo que será el programa de la auditoría ambiental, a ejercitar por este órgano de control y el CITMA, ta y como lo establece la Ley No. 107. Cuba.

58 Contrastar la obra en materia ambiental publicada por VIAMONTES GUILBEAUX, Dra.C. Eulalia de la Caridad Derecho ambiental cubano, en una compilación de autores. $Y$ otros artículos que en materia ambiental la prestigiosa autora ha incursionado en esta temática. UNIVERSIDAD DE LA HABANA. Cuba.

59 Consultar la obra de CARABALLO MAQUEIRA, Dr.C. Leonel El pensamiento ambiental cubano. Profesor titular. Facultad de Derecho de la UNIVERSIDAD DE LA HABANA. Especialista de la Dirección Jurídica del CITMA. Aborda en su tesis la necesidad de modificar conductas relacionadas con el tema ambiental, en pos del desarrollo sustentable con el medio ambiente. Cuba.

60 FERNANDEZ RUBIO-LEGRA, Dr.C. Ángel. Ver su obra sobre la Ley del medio ambiente en 150 preguntas y respuestas. Publicado por el Ministerio de Justicia. Cuba. INSTITUTO DE RELACIONES INTERNACIONALES.

61 REY SANTOS, MSc. Orlando. Retos en la implementación de derecho ambiental. Cuba. CITMA. 2006.

62 FOURNIER DUARTE, Dra.C. Niurka. Ver artículo sobre la aplicación de la JUSTICIA AMBIENTAL. Jueza del Tribuna Popular Provincial de Santiago de Cuba. Cuba.

63 MONZON BRUGERA, Dra.C. Yailen. Consultar su tesis doctoral sobre el Manejo Integrado de Zonas Costeras en Cuba, donde la autora hace referencia de los presupuestos del Derecho Ambiental. 2012. Universidad de Cienfuegos. Cuba.

64 ELIAS VEGA, MSc. Niobis. Consultar el informe de la tesis sobre el manejo integrado de zonas costeras, defendido por la autora en la Facultad de Derecho de la UNIVERSIDAD DE ORIENTE. Cuba.

65 CANOVAS GONZALES, Dr.C Daimar. Derecho del medio ambiente, editora Venezolana, donde el autor aborda la problemática de la protección del ambiente, desde su dimensión social. Cuba. responsabilidad ambiental, las herramientas de gestión, el Manejo Integral de las Zonas Costeras, el tratamiento de la justicia ambiental, el derecho administrativo ambiental desde 1980. Existiendo insuficiencias en el análisis relacionado con el tratamiento al control ambiental, en el orden teórico, doctrinal y legislativo.

Los autores al contextualizar todos estos criterios vertidos en su definición, le consideran como: el instrumento de la administración de la empresa que se ocupa de las rutinas de trabajo y procedimientos de esta, o de uno de sus sectores, referidos a la gestión ambiental, al nivel de cumplimiento con las leyes ambientales y la política de la empresa misma, es un procedimiento ordenado que tiene por objetivos básicos el examen y evaluación, periódica u ocasional, de los aspectos legales, técnicos y administrativos, relacionados con las actividades ambientales de la empresa, como un instrumento de análisis de su desempeño ambiental y de las acciones relativas a esos empeños, es además un instrumento de gestión que nos permite hacer una evaluación sistemática, periódica y documentada y objetiva de los sistemas de gestión y desempeño de los equipos (equipamientos) instalados en el establecimiento de una empresa, por fiscalizar y limitar el impacto de sus actividades sobre el medio ambiente.

Como componente o compartimiento de la auditoría social que consta en un examen o evaluación independiente, sistemático, periódico, documentado y objetivo, realizado por un equipo interdisciplinario de auditores ambientalistas (profesionales especializados en los campos contable-financiero-económico, de ciencias ambientales de biología, de ingeniería, de derecho, de ciencias sociales, y de experto generalista de la industria o del gobierno) todos ellos con conocimiento de las normas y capacitación en la aplicación de los respectivos procedimientos de las auditorias financieras y de gestión.

Es una evaluación sistemática para determinar si el sistema de control ambiental y el desempeño ambiental están de acuerdo con los programas de acción y el sistema está siendo efectivamente implantado y es adecuado para la política ambiental de la empresa. Es una evaluación objetiva y documentada del impacto de sus actividades del negocio sobre el ambiente, tiene por objeto apreciar, en un momento dado, el 
impacto que todo o parte de la producción o de la existencia de una empresa es susceptible de acarrear en el ambiente y aparece como una herramienta de gestión, que permite monitorear el avance de la gestión ambiental y destacar en forma temprana los riesgos potenciales.

Se considera finalmente, que existe consenso sobre que es una herramienta de gestión para conocer la gestión ambiental en una empresa, sus riesgos potenciales, su dimensión social, ejecutada por equipos multidisciplinarios, para determinar el grado de eficiencia en materia medioambiental. En Cuba se ve contextualizada en el sector empresarial que tiene implementado el sistema de perfeccionamiento, en la carpeta de gestión ambiental, no así en otras áreas del sector empresarial estatal y el no estatal, donde no se implementan de manera adecuada las políticas relacionadas con la protección al medio ambiente.

Pudimos analizar lo dispuesto por la organización internacional que agrupa a las Entidades Fiscalizadoras Superiores, quien la define como: la herramienta de planificación y gestión que le da una respuesta a las exigencias que requiere cualquier tipo de tratamiento del medio ambiente urbano, sirve para hacer un análisis seguido de la interpretación de la situación y el funcionamiento de entidades tales como una empresa o un municipio, analizando la interacción de todos los aspectos requerido para identificar aquellos puntos tanto débiles como fuertes en los que se debe incidir para poder conseguir un modelo respetable para con el medio ambiente.

A juicio de estos autores sí señalamos en el caso de una empresa estatal o no estatal, para qué y por qué realiza una auditoría ambiental de manera voluntaria, se determina que lo hace para cuantificar las operaciones industriales, determinando sí los efectos de contaminación que produce dicha empresa, están dentro del marco legal de la protección ambiental, para que tribute al desarrollo local esperado con producciones limpias. Esto no está muy interiorizado en el empresariado cubano, porque aún no existe una adecuada conciencia ambiental que permita con acciones positivas mitigar la problemática ambiental actual, recogida en la Estrategia Ambiental, aunque tenga como nota distintiva la obligatoriedad a través de un plan.
Estudios probatorios de la Evaluación de Impacto Ambiental, suelen llevarse a cabo para poder determinar si un nuevo desarrollo o una obra de expansión van a cumplir con los reglamentos impuestos durante el proceso de construcción del proyecto. Por lo que los autores la definimos como: la acción de control ambiental realizada por una EFS que permite conocer el resultado del impacto ambiental, en el que podrá monitorearse la gestión ambiental en que concurre una Persona Jurídica y determinar los riesgos en que pueda incurrir, para certificar su tecnología limpia.

Guardando relación con la auditoría de gestión, la auditoría de cumplimiento y la financiera dentro del derecho interno cubano. Los países tomados como referente en materia de derecho comparado, ejecutan esta acción de control por las normas ambientales creadas por la International Organization for Standarization; serie ISO 14 000, de estándares internacionales, que no es ley, pero sí los países la tienen registrada para hacer negocios, el cumplimiento y compromiso con el medioambiente tiene que mostrarse, como requisito para negociar reconocido en tratados internacionales, siendo barreras para el desarrollo del comercio internacional. ${ }^{66}$

Continuando con el análisis del derecho del medioambiente y dentro de este, el control ambiental a los recursos naturales como protección al bien jurídico ambiental, contamos con el estudio realizado por los profesores e investigadores del área jurídica de Latinoamérica, del Proyecto Planeta Verde, Caferrata y Rinaldi, el que concluyendo en su primera fase, sus resultados se coligen: "casi todos los países de América Latina y el Caribe presentan una estructura legal similar: en la cabeza, cláusulas constitucionales ambientales, luego una Ley General, Ley de Bases, Marco, u Orgánica, del Ambiente, y más abajo, leyes sectoriales ambientales". 67

66 Normas ISO 14001. Implementa el procedimiento de la auditoría ambiental. SGMA: Especificaciones y guías de uso. ISO 14004. SGMA: Directivas generales sobre principios, sistemas y técnicas de apoyo. ISO 14010. Pautas para Auditoría Ambiental: Principios generales. ISO 14011. Pautas para Auditoría Ambiental: Procedimientos. ISO 14012. Pautas para Auditoría Ambiental: Criterios de calificación de auditores ambientales. ISO 19011. Fundamentos de la Auditoría Ambiental. ISO 14020 a 14025. Ecoetiqueta ambiental ISO 14034. Indicadores de desempeño Ambiental ISO 14040 a 14049. Análisis del ciclo de vida ISO 14050. Vocabulario ISO 14062. Ecodiseño ISO 14064. Gases efecto invernadero hptt/www.iso.org

67 Informe del PNUMA "Planeta Verde", el que hace una relatoría 
Coincidente con los estudios anteriores realizados por el profesor Brañes Ballesteros; confirmados por el directivo de política ambiental del CITMA, Rey Santos, quien afirma,

(...) las normas constitucionales que se ocupan del medio ambiente constituyen una parte muy relevante del Derecho Ambiental. Ello es así porque dichas normas trazan pautas esenciales de obligada consideración por el legislador y, por tanto, guían el actuar del órgano legislativo. (...) Por otra parte, su carácter de norma estable supone que la modificación o derogación de la constitución está sometida a condiciones especiales, y su condición "rígida" determina que el proceder para tales cambios esté generalmente recogido en la propia constitución. Esta estabilidad se trasmite a los presupuestos ambientales que contiene, elementos que convierten a la normativa constitucional en un ámbito particularmente relevante para el análisis de la evolución y marcha del derecho ambiental. ${ }^{68}$

Brañes Ballesteros, resaltaba en sus estudios que:

(...) la compleja historia política reciente de gran mayoría de los 20 países que componen América Latina ha llevado a una renovación de sus instituciones, lo que se ha reflejado, entre otras cosas, en cambios constitucionales. Entre 1972 y 1999, 16 de los 20 países de la región se han dado nuevas Constituciones Políticas, que de diversas maneras han procurado incorporar las modernas preocupaciones de la sociedad latinoamericana. ${ }^{69}$

Lo aquí analizado en un primer resultado nos ha permitido reconocer que en estas nuevas Constituciones figuran un número importante de disposiciones que se refieren a la preocupación por la protección del medioambiente y la promoción de un modelo de desarrollo sostenible, que han venido a enverdecer estas leyes fundamentales

sobre la actual situación legislativa ambiental en la que se encuentra el área geográfica latinoamericana. Liderado por los profesores Dr. Néstor CAFERRATA y el Dr. Gustavo RINALDI. Argentina. 2013.

68 FERNÁNDEZ DE GATTA, Dionisio. Los principios y aspectos generales relacionados con la protección al medioambiente", la responsabilidad social corporativa y la auditoría ambiental. Universidad de Salamanca. España.2009.p.12 Coinciden LOPERENA ROTA, Demetrio. "Los principios del Derecho Ambiental." España.1998.p.13 CANOSA USERA, Raúl. "Protección jurídica del medio ambiente". Editora Fundación para el Análisis y Estudios Sociales. España. 2010.pp.5-79

69 Ibídem No. 55. desde el pasado siglo hasta el actual, lo que se refuerza con los mecanismos introducidos en relación con el control a los recursos naturales tanto para el sector estatal como el no estatal, tributando al desarrollo sostenible, que no es más que tributar a un desarrollo local adecuado, y que como baluarte se encuentra la de Ecuador, país Latinoamericano, como Estado parte del bloque económico del ALBA.

\section{La actividad de servicios públicos} Podemos señalar que la primera idea de servicio público, al igual que otras instituciones jurídicas administrativas, tienen lugar como mayoritariamente se le reconoce y concuerda la doctrina, en la Francia del siglo XVIII, partiendo desde la consolidación del movimiento revolucionario burgués, frente a la influencia de la nobleza en los cuerpos judiciales de este momento histórico.

Matilla Correa, expresó: "La noción de servicio público no sólo aparece aquí como una técnica que enmarca en el interior del ámbito jurídico administrativo una actividad de gestión, sino como criterio permite, además, evaluar la naturaleza iusadministrativa de otras actuaciones de las entidades públicas".70

70 MATILLA CORREA, Andry. "Derecho Administrativo y servicio público. Trazos inconclusos desde una perspectiva histórica". Revista jurídica UNAM, México D. F. p.402. Universidad de La Habana. hptt/www.juridicas.unam.mx. 2013. Es criterio de este autor sobre este tipo de actividad al considerarle como una actividad de control, en el caso de Cuba puede también entenderse como servicio público. En otros países este tipo de actividad la realizan sujetos privados, es una típica expresión de ejercicio de funciones públicas por parte de los privados, requieren ciertos títulos habilitantes para ello. En Cuba existe una confusión con el término servicio público, de ahí que muchos no lo entiendan como tal, desde su perspectiva la actividad de auditoría en Cuba es un servicio público que se concreta en cierta actividad de control en su contenido, es de titularidad pública, la realiza una entidad pública en función de un interés y se concreta en ciertas prestaciones que el contenido de control. En el país existe mucha asistemática y fragmentación en esa articulación. Hay que conocer bien esas categorías para poder articularlas y llegar a conclusiones a partir de lo complejo de nuestro andamiaje normativo, que por demás no tiene detrás un pensamiento de este tipo y no cree hoy que en la práctica cubana se logre entender eso Son coincidentes DUGUIT, León. "Las transformaciones del Derecho Público", Editora Colin, 3a ed. París, 1925, p. 51. Actividad cuyo cumplimiento debe de ser regulado, asegurado y fiscalizado por los gobernantes, es indispensable a la realización y al desenvolvimiento de la interdependencia social, de tal naturaleza que no puede ser asegurado completamente más que por la intervención de la fuerza gobernante. GARCIA DE ENTERRIA, Eduardo y otros. "Curso de derecho administrativo". Editora Marcial Pons. España.2003. "La actividad industrial y mercantil de los municipios", Revista de Administración Pública, No.17, 1955. GARRIDO FALLA, Fernando. "El concepto de servicio público en el derecho español" Universidad Complutense de Madrid, Revista de Administración Pública No.135.1994. 
Constituye reseñar además que el concepto de servicio público ha tenido diversas acepciones, en correspondencia con el momento histórico en que se ha escrito sobre el mismo. El nuevo constitucionalismo que se vislumbra en el área Hispanoamericana, de la cual somos parte, ha mostrado cierto interés en el reconocimiento de esta actividad. Siendo de sumo interés para el Estado legitimar en normas su consecución, en correspondencia a las modificaciones que se vienen realizando con los cambios económicos en el proyecto social cubano, por ser esta un eslabón fundamental dentro de la actividad administrativa, que aún no se vislumbra con una adecuada construcción doctrinal por parte de los saberes jurídicos en el país.

Dentro del derecho interno, visualizamos la estructuración de organización administrativa cubana, la que encuentra su asidero legal a partir del Decreto Ley 67 de 1983, como regulación jurídica medular de la estructura central de la Administración Pública; modificado posteriormente por el Decreto Ley 147 de 21 de 1994 y otros cuerpos legales que en este sentido han estado unificando actividades en este entramado orgánico-administrativo del país. Lo cual permite la funcionalidad, al menos general, a los OACEs y a los Órganos Locales del Poder Popular a través de sus Consejos de la Administración, siendo los encargados de la dirección de las actividades y servicios que a la Administración Pública les compete. ${ }^{71}$

En la determinación de una actividad como servicio público resultan indispensables una serie de elementos que dan al traste con su adecuada configuración. Estos elementos, también

$\overline{p .8 \text { Toda actividad técnica realizada de manera continua, }}$ regular y uniforme, tutelada por la Administración Pública y gestionada directamente por esta o indirectamente por sujetos independientes autorizados para ello, bajo un régimen jurídico especial y destinado a la satisfacción de un interés general. TOLEDO TOLEDO, Dalia. Tesis maestría: "La calidad en los servicios públicos como una estrategia para legitimar a los gobiernos locales". Universidad del Ismo. México D.F. (2008). LONGO, Francisco. "La nueva gestión pública en la reforma del núcleo estratégico del gobierno: experiencias latinoamericanas". Nueva Gestión Pública y regulación en América Latina. CLAD 2001.pp.8-73 CALLAFEL, Jorge. "Los servicios públicos". Editora Anuario Jurídico. Argentina.2007.pp.1-19

71 MINISTERIO DE JUSTICIA de la Republica de Cuba, donde se encuentra hospedada la gaceta oficial, disponible en hptt// www.gacetaoficial.cu, podrá consultar las normas jurídicas relacionadas con los Organismos de la Administración Pública en el país y el actuar de los Consejos de las Administraciones de cada territorio. denominados características, han posibilitado que en conjunto con los criterios y principio enarbolados pueda llegarse a definir con mayor exactitud al servicio público como categoría jurídica. Afortunadamente la doctrina se muestra pacífica y uniforme ante los mismos. Uno de los primeros elementos a tener en cuenta es la necesidad de carácter general; lógicamente si el fin del servicio público viene dado por solventar necesidades públicas, debe de partirse en primer lugar de la existencia de tal necesidad individual que se generaliza, de lo contrario no tendría caso. $^{72}$

Por otra parte se encuentra el sujeto prestador de la actividad, en este caso es evidente que se hace referencia a los órganos de la Administración Pública o el sujeto particular encargado de llevar a cabo la prestación. ${ }^{73}$

Otro de los elementos importantes del servicio público viene dado por la necesidad de una prestación regular, continua y uniforme, para que pueda satisfacer necesidades de las comunidades por sobre los intereses de quienes los prestan. ${ }^{74}$

Entre otros elementos de servicio público, no debe de olvidarse el importante elemento de la titularidad, es decir ¿Quién goza de ser el titular de la actividad que se realiza? En dirección a ello la doctrina responde prácticamente unánime al Estado. ${ }^{75}$ Por último y no menos importante, es lo que se refiere al régimen jurídico, según Jèze... "la

72 FERNÁNDEZ RUIZ Jorge. "Panorama " Ob. cit., p. 115. Son coincidentes REYNA ALFARO, Luis Miguel y otros...los servicios públicos provienen del interés público por sus actividades, y se traduce principalmente en control de tarifas y servicios... en Colectivo de autores. "Actualidad de los...Ob. cit.," "Los servicios públicos en el Perú: Una visión preliminar"), p. 595. BOQUERA OLIVER, José. "Derecho Administrativo", 10 edición, civitas, Madrid, 1996, p. 71.

73 REYNA ALFARO, Luis y otros... su prestación puede ser hecha tanto por un organismo público como por particulares, pero bajo la autorización, control, vigilancia y fiscalización del Estado con estricto apego al ordenamiento jurídico pertinente. Coincide ISLAS COLIN, Alfredo....el citado autor define este elemento bajo la calificación de orgánico, argumentando...En los servicios públicos los elementos orgánicos consisten en el aseguramiento de dicha actividad por un órgano de la Administración Pública, pero el Derecho Administrativo clásico permite, por una parte, que una persona privada pueda prestar el servicio público. en Colectivo de autores. "Actualidad de los...Ob. cit.,"(los servicios públicos en el Perú: una visión preliminar), p. 589.

74 ARIÑO ORTIZ, Gaspar. "Principios de Derecho Público Económico. (Modelo de Estado, gestión pública, regulación económica)". Universidad Autónoma de Madrid, Granada, 2001, p 522 .

75 ARIÑO ORTIZ, Gaspar. "Principios de...Ob.cit., p. 531. 
expresión servicios públicos, conviene reservarla a los casos de satisfacción de necesidades de interés general en que "los agentes públicos puedan recurrir, por los procedimientos del derecho público, a reglas que están fuera de órbita del derecho privado"?6

Como se ha podido observar de manera individual se ha pretendido mostrar algunos elementos sustanciales que componen en alguna medida los servicios públicos. Sin embargo no ha faltado en la propia doctrina otros autores que agrupan determinados elementos para configurar al servicio público.

2.1. Presupuestos de la actividad de servicios públicos vinculados con el control a los recursos naturales en Cuba

Los servicios públicos considerados por estos autores que guardan relación con el control al medioambiente, - a tenor de lo establecido en la doctrina analizada en el epígrafe anterior - vinculados al derecho ambiental, parten de la propia Ley No. 81. Están vinculados con las herramientas de gestión ambiental, complementados con las normativas reguladas en materia forestal, tributaria y urbanística. En materia de auditoría como expresión jurídica dentro del ordenamiento jurídico son los siguientes:

- El ordenamiento ambiental. (Este lo ejecuta en colaboración con el Ministerio de Economía y Planificación, a través de la Dirección de Planificación Física), utilizando para ello las normas urbanísticas como parte del Derecho Urbanístico. La propia norma señala que tendrá como objetivo principal asegurar el desarrollo sostenible del territorio a partir de considerar integralmente los aspectos ambientales y su vínculo con los factores económicos, demo-

76 GASTÓN JÈZE. "Principios generales... Ob.cit., p. 9. Coincidente con BOQUERA OLIVER, José María cuando destaca la condición sine qua non para que pueda crearse un servicio público, es decir que el legislador debe haber calificado de público el fin que será atendido, de esta manera el legislador y la Administración Pública decidirán cuales serán esos servicios sin contar aquellos en los que la Ley impone su creación a la Administración Pública por ser considerado necesario para satisfacer necesidades de carácter colectivo; y en los que se le deja discrecionalmente su creación,(servicios voluntarios). en "Derecho Administrativo", volumen I, 3ra Edición, Editorial Instituto de Estudios de Administración Local, Madrid, 1979, pp. 234-235. gráficos y sociales, a fin de alcanzar la máxima armonía posible en las interrelaciones de la sociedad con la naturaleza.

- La licencia ambiental. (La misma es concedida por los especialistas del CITMA, previa inspección ambiental realizada para la actividad que se pretenda ejecutar, en su concesión participan especialistas de otros organismos, como el Ministerio de Salud Pública, el Ministerio de la Agricultura, las Direcciones de Planificación Física entre otros). La norma le define como toda actividad susceptible de producir efectos significativos sobre el medio ambiente o que requiera de un debido control a los efectos del cumplimiento de lo establecido por la legislación ambiental vigente, estará sujeta al otorgamiento de una licencia ambiental por el CITMA de conformidad con lo que al respecto estipule este organismo, el que establecerá asimismo los tipos y modalidades de dicha licencia.

- La evaluación de impacto ambiental. (Este tipo de acción es realizada por especialistas del CITMA, aunque la ley dispone que pueden participar otros especialistas convocados para realizar dicha evaluación, la que no se ejecuta al 100\% de la actividad en el país) la Ley No. 81 en este particular define que será obligatorio someter a la consideración del CITMA, a fin de que se efectúe el proceso de evaluación de impacto ambiental correspondiente, los nuevos proyectos de obras o actividades.

- El Sistema de Inspección Ambiental Estatal. (Es un sistema diseñado por el organismo, desde su estructura central, provincia y municipal) Estableciendo que los órganos y organismos estatales que participan en el Sistema de Inspección Ambiental Estatal incluirán en sus sistemas de inspección los aspectos requeridos para garantizar la protección del medio ambiente en sus respectivas esferas, para lo cual actuarán en coordinación con el CITMA.

- Los regímenes de responsabilidad administrati$v a$, civil y penal. Son los que se establecen en la Ley marco ambiental, que sustantivamente 
se derivan al ejercitar la responsabilidad en el cumplimiento de lo regulado en el Código Penal, el Código Civil, y en la aplicación del Derecho Administrativo Sancionador por los que poseen competencia y jurisdicción.

- La auditoría ambiental (acción de control realizada por especialistas de la CGR en sus tres niveles) así como dentro de los OACEs y sociedades civiles acreditadas en el propio órgano, se ejecuta según dispone la doctrina consultada cuyo fin está destinado a certificar las tecnologías limpias de una entidad auditada. Lo cual aparece preceptuado en la Ley No. 107 y en el Acuerdo del Consejo de Estado reglamentando esta actividad, así como en los programas de auditoría establecidos por este órgano de control.

Los autores consideran que existen otros servicios públicos relacionados con la protección a los recursos naturales como son los de la distribución del agua y el de la recolección de los desechos sólidos, entre otros, que de una manera u otra la Administración Pública norma conductas hacia sus administrados (ciudadano social), utilizando para ello normativas administrativas, que guardan relación vertical y horizontal con el derecho ambiental; que aún no tienen un tratamiento adecuado en los sistemas contables empresariales (subsistema de contabilidad verde) y en el derecho interno.

Hoy dentro del ordenamiento jurídico cubano tienen una expresión normativa que se fundamenta en un eje administrativo para su cumplimiento por parte de la Administración Pública hacia sus administrados, aún sesgada sin una adecuada construcción doctrinal por parte del área académica en el país. Siendo a criterio de estos autores lo que aún no permiten que exista un reconocimiento del Derecho Administrativo Ambiental.

\subsection{El control ambiental, una herramienta de gestión ambiental para el desarrollo local como actividad de los servicios públicos de la Administración}

El control al medioambiente se realiza por los OACEs y los órganos del control del Estado, como por los Consejos de la Administración en cada territorio, en correspondencia con la división político administrativa del país. La Ley No. 81 establece que será el CITMA el organismo que ejercitará el control al medioambiente, señalando por demás que tienen además competencia y jurisdicción en esta actividad otros organismos como son el Ministerio de Salud Pública, quien ejercita la inspección sanitaria estatal, al amparo de lo que dispone la Ley No. $41^{77}$ y el resto de las normativas y disposiciones administrativas que la complementan.

En el Ministerio de la Agricultura, le corresponde ejercitar la inspección en materia forestal, la que ejercita con su cuerpo de inspectores, amparados en lo que se regula en la Ley No. $85 .{ }^{78}$ Otro organismo que tiene competencias en este sentido es el Ministerio de Trabajo y Seguridad Social, quien a través del control a la seguridad y salud laboral, ejercita la inspección laboral dentro del sector empresarial. Lo ejecuta en cumplimiento de lo preceptuado en la Ley No. 13 y las disposiciones que le complementan y actualizan en este sentido. ${ }^{79}$

Por lo que a criterio de estos autores son estos tres organismos los que mayor implicancia poseen en el control al medioambiente, estando en correspondencia con lo que se dispone en la Ley marco ambiental cubana vigente.

Ahora, con respecto a los órganos que tienen vínculo con el control a los recursos naturales, se encuentra en primer orden la FGR, cumpliendo el mandato establecido en la Ley No. 83. Lo ejercita, al ser la veladora del cumplimiento de la legalidad y lo hace a través de las Verificaciones Fiscales, comprobando el cumplimiento de las

77 Consultar el sitio web del MINISTERIO DE JUSTICIA de la Republica de Cuba, donde se encuentra hospedada la gaceta oficial, disponible en hptt//www.gacetaoficial.cu, en cuanto a la Ley de la Salud Pública, en relación con el actuar del Ministerio de Salud Pública y en especial la Inspección Sanitaria Estatal.

78 Consultar el sitio web del MINISTERIO DE JUSTICIA de la Republica de Cuba, donde se encuentra hospedada la gaceta oficial, disponible en hptt//www.gacetaoficial.cu, en relación con las funciones del Ministerio de la Agricultura en la política forestal, a través de la Ley Forestal y el actuar de sus cuerpos de inspección estatal, vinculados al derecho administrativo sancionador.

79 Consultar el sitio web del MINISTERIO DE JUSTICIA de la Republica de Cuba, donde se encuentra hospedada la gaceta oficial, disponible en hptt//www.gacetaoficial.cu, en relación con la inspección estatal en materia de seguridad y salud, ejercitada por parte del Ministerio de Trabajo y Seguridad Social. 
políticas establecidas por el Estado en relación a la temática abordada. ${ }^{80}$

El otro órgano con competencia es la CGR, que al amparo de lo preceptuado en la Ley No. 107 y en el Decreto Ley No. 15981, ejercitará el más alto control por parte del Estado en cumplimiento de su mandato, a través de la auditoría. Acción esta que no guarda relación con la inspección al discernir en su procedimiento y formas de ejecución, como en la persona que la ejecuta, la que tendrá que contar con una certificación como auditor o contralor.

Los autores concuerdan en que esta actividad de la auditoría ambiental o ecoauditoría, es un servicio público que presta la Administración Pública a sus administrados y a las personas naturales, partiendo del propio concepto de servicio público y de las características que le distinguen. Destinado dentro del desarrollo local a identificar dentro del sector empresarial a los que contaminan el medioambiente, certificándoles o no su producción como limpia, un reto por la obsolescencia tecnológica de la actual industria del país, muchas de estas con más de 50 años de explotación y de heterogeneidad en el sistema empresarial, hoy avocados a implementar un modelo económico que permitirá según su diseño evolucionar en el mercado internacional con los productos que seamos capaces de producir debidamente certificados.

Es por ello que la Administración Pública ha concebido en su derecho interno nuevas figuras que de una manera u otra tienen un vínculo con el control ambiental, es el caso de la normativa tributaria, con la Ley No. 113, la que irradia a la aplicación del ecoimpuesto o impuesto ambiental, permitiéndole tomar estrategias en pos de mitigar acciones negativas que contra el medio ambiente se hayan suscitado, al tener un fondo dinerario para tomar acciones para revertir o mitigar la situación adversa ambiental. ${ }^{82}$

80 Consultar el sitio web del MINISTERIO DE JUSTICIA de la Republica de Cuba, donde se encuentra hospedada la gaceta oficial, disponible en hptt//www.gacetaoficial.cu, en relación con la Ley de la Fiscalía General de la República de Cuba.

81 Consultar el sitio web del MINISTERIO DE JUSTICIA de la Republica de Cuba, donde se encuentra hospedada la gaceta oficial, disponible en hptt//www.gacetaoficial.cu, actual normativa en Cuba que regula la auditoria y su ejercicio en el territorio nacional.

82 Consultar el sitio web del MINISTERIO DE JUSTICIA de la Republica de Cuba, donde se encuentra hospedada la gaceta
Es criterio de los autores considerar que aún quedan sesgos por implementar en nuestro derecho interno, ejemplo de ello es el caso de la contabilidad dentro del sistema empresarial, la que no recoge los riesgos ambientales en sus asientos contables (contabilidad verde), otro ejemplo es el seguro ambiental, el que permitiría cubrir los riesgos a través de la póliza concertada con las aseguradoras del país ${ }^{83}$.

Por lo tanto lejos de reconocerse que la legislación en materia ambiental en el país es adecuada, está necesitada de actualización y evolución, a tono con las situaciones fácticas implementadas y con solución en otros sistemas de derecho que han sido contrastados por los autores de este material.

\section{CONCLUSIONES}

La acción de control al medioambiente a través de la auditoría ambiental, como función estatal, será ejercitada al amparo de la Ley No. 107, a través de los programas de control establecidos por la Contraloría General de la República a las personas jurídicas y naturales, con el objeto de certificar la producción+limpia, cuyo resultado será mitigar los problemas medioambientales, haciendo competitiva en el mercado la producción mercantil con su ecoetiqueta, como servicio público de la Administración estatal.

Las ciencias jurídicas y las ciencias contables, deberán marchar unidas en pos de un desarrollo y equilibrio sustentable para preservar el medio ambiente.

La Ley de la Auditoría y la Ley del Medio Ambiente, deberán ser actualizadas atendiendo a que:

- De estas parten la identificación de los principios jurídicos y la consolidación de las técnicas

oficial, disponible en hptt//www.gacetaoficial.cu, relacionada con la actual política tributaria del país.

83 A través de la ESEN o la ESICUBA, actuales empresas en materia de seguros establecidas en Cuba. Legitimada a tenor del Decreto Ley No. 263 y las normativas sustantivas de esta actividad. Son coincidentes VIGURI PEREA, Ángel. "La responsabilidad en materia ambiental: el seguro ambiental". La importancia de adquirir la póliza contra los adversos ambientales en la empresa. Universidad de Pittsburgh. Estados Unidos de América.2011.p.53. CABEZA ARES, Alberto. "Los seguros de responsabilidad civil medioambiental en la obligación de reponer y restaurar el medioambiente alterado". Editora Universidad de León.España.2003.p.67 
jurídicas relacionadas con la tutela del control ambiental, hoy en contradicción.

- Con la comprensión y regulación jurídica de esta acción de control, permitirán alcanzar las metas y objetivos que orientan la acción de control en respuesta a la función estatal como política pública, en correspondencia con las directrices establecidas por las Entidades Fiscalizadoras Superiores.

- En el derecho interno cubano, no hay un tratamiento adecuado a la contabilidad en relación con la debida protección al medio ambiente, como política pública estatal, relacionada con el desarrollo sustentable, tributario al desarrollo local.

- La norma sustantiva cubana, no establece la póliza de seguro ambiental, relacionada con la comisión del daño ambiental por parte de las personas naturales y jurídicas.
- La ecotributación, modernizada con la implementación a tenor de la Ley No. 113, tendrá que ser contextualizada por el empresariado cubano, para coadyuvar a mitigar los problemas ambientales.

- La educación superior tendrá que proyectar estudios superiores relacionados con estudios en ingeniería ambiental o en ciencias ambientales, que permitan dar una respuesta adecuada a los actuales problemas ambientales.

- Fomentar estudios para el reconocimiento doctrinal sobre los servicios públicos en materia ambiental.

Se requiere con urgencia fomentar estudios académicos que tributen a la conformación en materia doctrinal del derecho administrativo ambiental en el país por parte de los juristas dedicados al estudio de esta rama de las ciencias jurídicas.

\section{BIBLIOGRAFÍA}

- ARMADA TRABAS, E. Metodología para desarrollar Auditorías de Gestión en Cuba. Tesis en Opción al grado científico de Doctor en ciencias económicas. Editora Ministerio de Educación Superior. La Habana. Cuba. 1997

- _ Curso Teoría de la auditoría. Universidad de La Habana. Ministerio de Educación Superior. Cuba. 2011

- AgUILERA MESA, I. Proyecto de Programas para la realización de auditorías de gestión ambiental. Tesis en opción al grado científico de Master en Contabilidad y Auditoría. Revista de Auditoría y Control. Contraloría de la República. No. 12. La Habana. Cuba. 2004

- ANTUNEZ SANCHEZ, A. F. La auditoría en Cuba. Tesina del Diplomado Derecho de Empresas. Facultad de Derecho. Universidad de Oriente. Cuba. 2002.
- L_Los problemas ambientales en Granma. La auditoría ambiental como herramienta de Gestión. Tesis de la Especialidad Derecho de Empresas. Facultad de Derecho. Universidad de Oriente. Cuba. 2005

- Aspectos generales del medio ambiente y de la gestión ambiental empresarial. Grupo de trabajo estatal. Bahía Habana. Autores: Socarras Stable, Johanna y otros. Producciones más limpia, consumo sustentable. p.49. Auditorías ambientales. Derecho urbanístico. Cuba. 2009

- ANTUnes, Paulo de Besa. Direito Ambiental. Ed. 14, Editora Lumen Juris. Rio de Janeiro. Brasil. 2010.

- ÁGUILA CARRALERO, A. y otros. Consideraciones sobre la tributación ecológica como una alternativa para la protección ambiental. Facultad de Derecho. Universidad de Camagüey. Cuba. 2012. 
- ARIÑO ORTIZ /J. M. DE LA CUÉTARA MARTÍNEZ/J.L. MARTÍNEZ LÓPEZ-MUÑIZ, "Significado actual de la noción de servicio público". en la obra "El nuevo servicio público", M. Pons, Madrid, 1997.

- BRAÑES BALLESTEROS. R. Manual de Derecho Ambiental Mexicano. Edición CITMA. La Habana. Cuba. 2005.

- __ Informe sobre el desarrollo del Derecho Ambiental Latinoamericano. Su aplicación después de diez años de la Conferencia de las Naciones Unidas sobre el Medio Ambiente y el Desarrollo, PNUMA, México D.F. 2001.

- ___ L L L fundación del Derecho Ambiental en América Latina. Chile. 2003.

- BACIGALUPO SAGGESE, M. "Servicio público y derechos fundamentales". boletín de la Facultad de Derecho, núm. 21, 2003.

- BREWER-CARÍAS. A "Comentarios sobre la noción del servicio público como actividad prestacional del Estado y sus consecuencias". Comentarios monográficos. Universidad Central de Venezuela.

- BERNAl PISFIL, F. Auditoría Ambiental o Ecoauditoría. Revista Actualidad Empresarial, № 201.Colombia. 2010.

- BELTRAO, A.F.G. Direito Ambiental. Editora Metodo. Sao Paulo. 2da ed. Brasil. 2010.

- BELLORIO, D. Tratado de Derecho ambiental. Editora AdHoc s.r.l. Argentina. 1997.

- BUSTAMANTE ALSINA, J. Derecho Ambiental. Fundamentación normativa. Editora Montecorvo. España. 2010.

- CARABAllo MAQUEIRA, L. El pensamiento ambiental cubano. Especialista principal de la Dirección Jurídica del CITMA. Cuba. 2000

- _. La presencia de la concepción de producción más limpia en la legislación ambiental cubana.Cub@: Medio Ambiente y Desarrollo; Revista electrónica de la Agencia de Medio Ambiente. Cuba. 2005.

- CAFFERATA, Dr. N. A., Introducción al Derecho Ambiental, Editora INE- Semarnat, México D.F., 2004.
- CANOVAS GONZALEZ, D. Estudios sobre Derecho del Ambiente. Editora Vadell hermanos. Valencia. Venezuela. 2011.

- COMA, M. "Servicio público y empresa pública: reflexiones sobre las llamadas sociedades estatales", núm. 84, septiembre-diciembre 1977.

- COUZINET, P. "La fiscalización de la actividad administrativa de las autoridades locales en Francia". 19(56) 313-27.

- CRUZ SARDIÑAS, T. El derecho al desarrollo sostenible. Una actualización obligada para la doctrina del Derecho Ambiental. I Congreso Politica, Derecho y Justicia Ambiental. 9na Convención Internacional sobre Desarrollo y Medio Ambiente. La Habana. Cuba. 2013.

- DROMI, R. "Derecho administrativo", 5. a edición, Ediciones Ciudad Argentina, Buenos Aires, 1996.

- DUGUIT, L. "Las transformaciones del Derecho Público". Traducción de Adolfo POSADA y Ramón JEAN. Segunda ed. un volumen en $8 .^{\circ}$ pesetas 6.

- ESCRIBANO COLLADO, P. "El usuario ante los servicios públicos: precisiones acerca de su situación jurídica", núm. 82, enero-abril 1977.

- FONT ARANDA, M. y autores. La auditoría ambiental, una perspectiva global y nacional. Centro de Estudios del Instituto de Turismo Matanzas. Universidad de Matanzas. Cuba. 2011.

- FERNÁNDEZ-RUBIO LEGRÁ, Á. Ley 81 en más de 150 preguntas y respuestas. Editora MINJUS. La Habana. Cuba. 1999.

- FERNÁNDEZ BULTÉ, J. "Teoría del Estado", Primera Parte, Editorial Félix Varela, La Habana, 2004.

- “Teoría del Derecho", Primera Parte, Editorial Félix Varela, La Habana, 2004.

- GARCÍA DE ENTERRÍA, Dr. E. Curso de Derecho Administrativo. Parte 1 y 2. Editora Félix Varela. La Habana. Cuba. 2007.

- GARCINI GUERRA, Dr. H. Derecho Administrativo. Editora Pueblo y Educación.. La Habana. Cuba. 1986. 
- GARRIDO VÁSQUEZ, R. ¿La economía verde o la economía del desarrollo sostenible? Retos actuales y respuestas a los lineamientos del 6to Congreso del Partido Comunista de Cuba. I Congreso de Politica, Derecho y Justicia. 9na Convención Internacional sobre Desarrollo y Medio Ambiente. Cuba. 2013.

- GONZÁLEZ MALAXECHEVARRÍA, Á. La Auditoría medioambiental, su evolución histórica y entorno político-institucional. Madrid. España. 1997

- GARCÍA DE ENTERRÍA, E. "La actividad industrial y mercantil de los municipios", Revista de Administración Pública, núm. 17, 1955.

- _El servicio público en los transportes urbanos", núm. 10, enero-abril 1953.

- ___ "Sobre la naturaleza de la tasa y las tarifas de los servicios públicos", núm. 12, septiembre-diciembre 1953.

- HERNÁNDEZ AGUILAR, O. y otros. Fundamentos jurídicos constitucionales de la gestión ambiental en Cuba. Propuestas para su perfeccionamiento desde una perspectiva integral. I Congreso de Politica, Derecho y Justicia Ambiental. 9na Convención Internacional sobre Desarrollo y Medio Ambiente. Cuba. 2013.

- ISLAS COLIN. A. en Colectivo de autores. "Actualidad de los servicios públicos en Iberoamérica". (El servicio público en el Derecho francés"). Universidad Autónoma de México, 1aㅡ ed. 2008.

- JAQUENOD DE ZSOGON, S. El Derecho Ambiental y sus Principios Rectores, 3르. ed., Editora Dykinson, S.L, 1991. U.S.

- Jaquenod de Zsogon, S. Derecho ambiental. Editora Dykinson. España. 2004.

- Juste Ruiz, J. La evolución del Derecho Internacional del medio ambiente. Universidad de Valencia. España. 2007.

- JORDANO FRAGA, J., El Derecho Ambiental del Siglo XXI. Revista Electrónica de Derecho Ambiental, 09, julio 2003. En: http:// huespedes. cica.es/aliens/gimadus/09/ dcho_amb2_XXI.htm (visitado el 18 de enero de 2009). España.

- JUSTE RUIZ, José. La evolución del Derecho Internacional del medio ambiente. Universidad de Valencia. España. 2007.

- La inspección ambiental estatal. Agencia del Medio Ambiente. CITMA. Criterios sobre la auditoría ambiental y sobre la inspección estatal. CITMA. Cuba. 2007.

- La fiscalización superior en los umbrales del siglo xxi. Auditoría ecológica, revista OLACEFS. Volumen I, no. 4. pp. 3-25. Autora: Martínez Sanz, Maria Luz. 1993.

- LOZANo CUTANDA, B. Derecho Ambiental Administrativo, 5ta ed, Editora Dykinson. España. 2004.

- MATILlA CORREA, A, Comentarios sobre las fuentes del derecho administrativo cubano (excepto el reglamento)", en Castanedo Abay, A y otros., Temas de Derecho Administrativo Cubano, T I, Editora Félix Varela, La Habana, Cuba. 2004.

- MATILlA CORREA, A. "Introducción al régimen jurídico de las concesiones administrativas en Cuba". editorial universitaria. La Habana, 2009.

- en Colectivo de autores. "Actualidad de los servicios públicos en Iberoamérica". (Trazos inconclusos desde una perspectiva histórica). Universidad Autónoma de México, 1aㅡ ed. 2008.

"Notas sobre la ley y el principio de legalidad en el ordenamiento jurídico cubano", en AA. VV., Memorias del VI Foro Iberoamericano de Derecho Administrativo. VIII Jornadas de Derecho Constitucional y Administrativo, Universidad Externado de Colombia, Bogotá, 2007.

"Observaciones sobre el régimen legal vigente de las concesiones administrativas en Cuba". www.juridicas. unam 2012. 
- MARTín MATEO, Dr. R. Manual de Derecho Ambiental, 2da edición, Editora Trivium, S. A, Madrid, España. 2001.

- _ Tratado de Derecho Ambiental, Volumen I, 1ra edición, Editora Trivium S.A., Madrid, España. 1991.

- MARTÍN MATEO, R. Derecho administrativo. Tomo I, 6ta ed. Editora Trivium, España. 1997.

- MORA RUIZ, M. Tendencias del Derecho Administrativo. El Derecho Administrativo Ambiental: Transformaciones en el Derecho Administrativo general. Revista Derecho y Conocimiento. Universidad de Huelva. España. 2012.

- MEMBIELA GUAITA, A. "La municipalización de servicios públicos. Especial-mente referida al abastecimiento de agua de las poblaciones". Prólogo del Excmo. Sr. D. Carlos Ruiz del Castillo. Publicaciones del Instituto de Estudios de Administración Local, Madrid, 1950.

- MOEELL OCAÑA, L. “La evolución y configuración actual de la actividad administrativa sanitaria". 63(70) 131-65.

- Normas de auditoria. Contraloría General de la República de Cuba. Actualizadas por las normas de las EFS (INTOSAI) y las Normas Internacionales de Auditoría. 2012.

- NIETO, Dr. A. Derecho Administrativo Sancionador. Editora TECNOS. 2da. edición. España. 1994.

- OJEDA MESTRE, Dr. R. Secretario General de la Corte Internacional de Arbitraje y Conciliación Ambiental. México. Las cien caras del Derecho Ambiental. México. 2012.

- Prácticas de producción más limpias. Colectivo de autores. Manual de formación ambiental básica. La Habana: Cuba. Capacidad 21. PNUD-CITMA. 2007

- ORTEGA ÁlVAREZ, L. "Servicios públicos y usuarios de servicios" Revista de Administración Pública. Enero-agosto 2005.
- PEREZ VAqUeRO, C. Diez claves para entender el Medio Ambiente. UNIVERSIDAD DE VALLADOLID. España. 2012.

- PARÉS SALAS, A. "El contencioso de los servicios públicos". Consideraciones en torno al artículo 259 de la Constitución y a derecho fundamental a la adecuada prestación de los servicios públicos. Revista de Derecho Administrativo. № 12.

- REY SANTOS, O. Evaluación sobre la implementación de la Ley 81/97 Del Medio Ambiente a ocho años de su promulgación, en Di Cagno, V., La Protección del Medio Ambiente en Cuba, Editora Ciencias Sociales, La Habana, Cuba. 2005.

- __ Instrumentos de la gestión ambiental", en Viamontes Guilbeaux, E. C y otros., Derecho Ambiental cubano, 2da ed, Editora Félix Varela, La Habana, Cuba. 2007.

- REYNA ALFARO y Karen VENTURA SAAVEDRA. en Colectivo de autores. "Actualidad de los servicios públicos en Iberoamérica". ("Los servicios públicos en el Perú: Una visión preliminar"). Universidad Autónoma de México, 1aㅡ ed. 2008.

- RIVERO Y SERN, E. "La protección del usuario a los servicios públicos", núm 87, septiembre-diciembre 1978.

- RODRÍGUEZ-ARANA MUÑOZ, J. en Colectivo de autores. "Actualidad de los servicios públicos en Iberoamérica". (Sobre el servicio público universal en materia de telecomunicaciones). Universidad Autónoma de México, 1aㅡ ed. 2008.

- QUINTERO TIRADO, M. El derecho procesal ambiental y la tutela efectiva. España. 2012.

- VILLEGAS MORENO, J. L. Derecho Administrativo Ambiental. Editora Sin Límite CA. Venezuela. 2009.

- VIAMONTES GUILBEAUX, E. Compendio de Legislación Ambiental. Tomo I. Editora Félix Várela. Cuba. 1998. 
- — E. C y otros., Derecho Ambiental cubano, 2 da edición, Editora Félix .Varela, La Habana, Cuba. 2007.

- Vita Roso, J. La auditoría jurídica como actividad multidisciplinaria y el uso de tecnologías modernas. Facultad de Derecho, Ciencias Políticas y Relaciones Internacionales Universidad Tecnológica del Perú. 2009.

- VALLS HERNÁNDEZ, S. en Colectivo de autores. "Actualidad de los servicios públicos en Iberoamérica”.( La noción del servicio público en el Estado Social de Derecho). Universidad Autónoma de México, 1aㅡ ed. 2008.

- VIllabella ARMENGOL C. M. "Historia Constitucional y Poder Político en Cuba!, Ácana, Camagüey, 2009.
"La investigación y comunicación científica en la ciencia jurídica". ed. Instituto de Ciencias Jurídicas de Puebla. 2009.

- _ "Selección de Constituciones iberoamericanas", Félix Varela, La Habana, 2004.

- VILlar EZCURRA, J. L. "El derecho a la educación como servicio público”, núm. 88, enero-abril 1979.

- WALINE, M. "La noción de servicio público", en LL, t. 75.

- ZANOBINI, G "Curso de Derecho Administrativo", Volumen I. Parte General. Ediciones ARAYÚ. Buenos Aires. 1954.

- ZUGALDÍA ESPINAR, J. M. Delitos contra el medio ambiente y responsabilidad criminal de las personas jurídicas. Consejo General del Poder Judicial. España. 1997. 